ARTI-21CR/611-50060-01

\title{
USING ACID NUMBER AS A LEADING INDICATOR OF REFRIGERATION AND AIR CONDITIONING SYSTEM PERFORMANCE
}

Final Report

July 2003

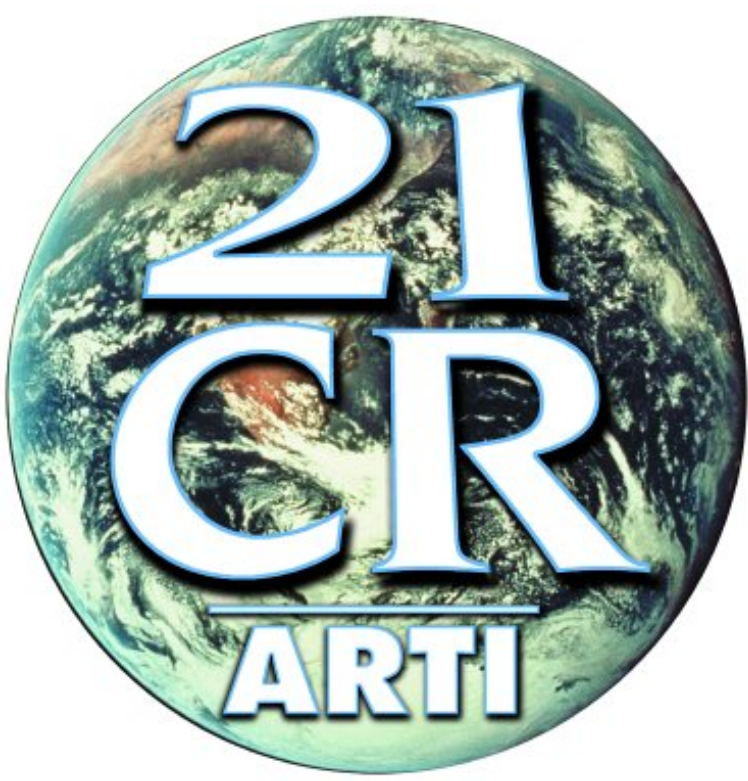

Dennis Cartlidge and Hans Schellhase

POWERTECH LABS INC.

$1238888^{\mathrm{TH}}$ Avenue

Surrey, British Columbia, Canada, V3W 7R7

Prepared for the

AIR-CONDITIONING AND REFRIGERATION TECHNOLOGY INSTITUTE

4100 N. Fairfax Drive, Suite 200, Arlington, Virginia 22203

Distribution A - Approved for public release; further dissemination unlimited. 


\section{DISCLAIMER}

This report was prepared as an account of work sponsored by the Air-Conditioning and Refrigeration Technology Institute (ARTI) under its "HVAC\&R Research for the $21{ }^{\text {st }}$ Century" (21-CR) program. Neither ARTI, the financial supporters of the 21-CR program, or any agency thereof, nor any of their employees, contractors, subcontractors or employees thereof - makes any warranty, expressed or implied; assumes any legal liability or responsibility for the accuracy, completeness, any third party's use of, or the results of such use of any information, apparatus, product, or process disclosed in this report; or represents that its use would not infringe privately owned rights. Reference herein to any specific commercial product, process, or service by trade name, trademark, manufacturer, or otherwise, does not necessarily constitute nor imply its endorsement, recommendation, or favoring by ARTI, its sponsors, or any agency thereof or their contractors or subcontractors. The views and opinions of authors expressed herein do not necessarily state or reflect those of ARTI, the 21-CR program sponsors, or any agency thereof.

Funding for the 21-CR program provided by (listed in order of support magnitude):

- U.S. Department of Energy (DOE Cooperative Agreement No. DE-FC05-99OR22674)

- Air-Conditioning \& Refrigeration Institute (ARI)

- Copper Development Association (CDA)

- New York State Energy Research and Development Authority (NYSERDA)

- California Energy Commission (CEC)

- Refrigeration Service Engineers Society (RSES)

- Heating, Refrigeration and Air Conditioning Institute of Canada (HRAI)

Available to the public from

U.S. Department of Commerce

National Technical Information Service

5285 Port Royal Road

Springfield, VA 22161

(703) 487-4650

Available to U.S. Department of Energy and its contractors in paper from

U.S. Department of Energy

Office of Scientific and Technical Information

P.O. Box 62

Oak Ridge, TN 37831

(423) 576-8401 


\section{USING ACID NUMBER AS A LEADING INDICATOR OF REFRIGERATION AND AIR CONDITIONING SYSTEM PERFORMANCE}

\section{Final Report}

July 2003

Dennis Cartlidge

Hans Schellhase

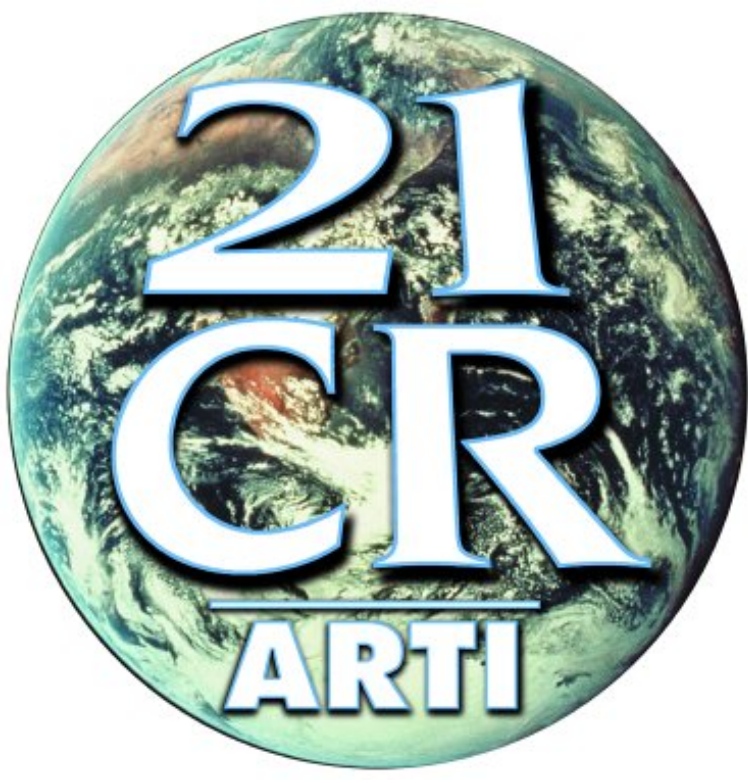

Prepared for the

AIR- CONDITIONING AND REFRIGERATION TECHNOLOGY INSTITUTE Under ARTI 21-CR Program Contract Number 611-50060-01

This research project is supported, in whole or in part, by U.S. Department of Energy grant number DE-FC05990R22674: ARTI 21 ${ }^{\text {st }}$ Century Research Program. 


\section{EXECUTIVE SUMMARY}

Air conditioning and refrigeration equipment needs to provide long-term reliable use. However, over long periods of time, stress induced deterioration of the refrigerant and/or lubricant will occur which can cause changes in the system chemistry resulting in decreased operating efficiency and potentially can lead to a failure of the system. A number of degradation processes contribute to the deterioration and are reflected by changes in parameters such as acidity, moisture content, viscosity, dissolved metal content, etc., which are all related to the formation of increasing amounts of acids over time. Total acid number (TAN), which includes both mineral acids and organic acids, is therefore a useful indicator which can be used to monitor the condition of the system in order to perform remedial maintenance, when required, to prevent system failure. A literature review was performed to assess the acidity characteristics of the older mineral oil and newer polyolester (POE) refrigeration systems as well as to evaluate acid measuring techniques used in other non-aqueous systems which may be applicable for refrigeration systems.

Failure in the older chlorofluorocarbon/hydrochlorofluorocarbon (CFC/HCFC) / mineral oil systems was primarily due to thermal degradation of the refrigerant which resulted in the formation of hydrochloric and hydrofluoric acids. These are strong mineral acids, which can, over time, severely corrode the system metals and lead to the formation of copper plating on iron surfaces. The oil lubricants used in the older systems were relatively stable and were not prone to hydrolytic degradation due to the low solubility of water in oil.

The refrigerants in the newer hydrofluorocarbon (HFC)/POE systems are much more thermally stable than the older $\mathrm{CFC} / \mathrm{HCFC}$ refrigerants and mineral acid formation is negligible. However, acidity is produced in the new systems by hydrolytic decomposition of the POE lubricants with water to produce the parent organic acids and alcohols used to prepare the POE. The individual acids can therefore vary but they are generally $\mathrm{C}_{5}$ to $\mathrm{C}_{9}$ carboxylic acids. Organic acids are much weaker and far less corrosive to metals than the mineral acids from the older systems but they can, over long time periods, react with metals to form carboxylic metal salts. The salts tend to accumulate in narrow areas such as capillary tubes, particularly if residual hydrocarbon processing chemicals are present in the system, which can lead to plugging.

The rate of acid production from POEs varies on a number of factors including chemical structure, moisture levels, temperature, acid concentration and metals. The hydrolysis rate of reaction can be reduced by using driers to reduce the free water concentration and by using scavenging chemicals which react with the system acids.

The critical TAN value is the acid level at which remedial action should be taken to prevent the onset of rapid acid formation which can result in system failure. The level of $0.05 \mathrm{mg} \mathrm{KOH} / \mathrm{g}$ of oil was established for $\mathrm{CFC} /$ mineral oil systems based on analysis of 700 used lubricants from operating systems and failed units. There is no consensus within the refrigeration industry as to the critical TAN value for HFC/POE systems, however, the value will be higher than the 
$\mathrm{CFC} /$ mineral oil systems critical TAN value because of the much weaker organic acids produced from POE. A similar study of used POE lubricants should be performed to establish a critical TAN limit for POE systems.

Titrimetric analysis per ASTM procedures is the most commonly used method to determine TAN values in lubricants in the refrigeration industry and other industries dealing with lubricating oils. For field measurements, acid test kits are often used since they provide rapid, semi-quantitative TAN results. Ion chromatography is a useful technique for the analysis of the POE samples since it allows the determination of individual organic acids as well as ionic degradation products.

Alternative acid measuring techniques such as free radical measurement and voltammetry, which are employed in other non-aqueous fields, may also be applicable to refrigeration systems and should be investigated. If successful, these techniques may provide an earlier indication of refrigeration system deterioration than the currently used titrimetric method. 


\section{ACKNOWLEDGEMENTS}

This study was sponsored by the Air-Conditioning and Refrigeration Technology Institute (ARTI). We would like to acknowledge the support of Michele Darbeau, ARTI Project Monitor.

We would also express our appreciation to Mr. Erik Korolenko and Mr. Gordon Ashby for their assistance in translating foreign language documents. 


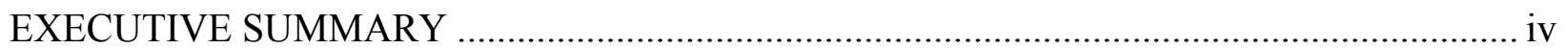

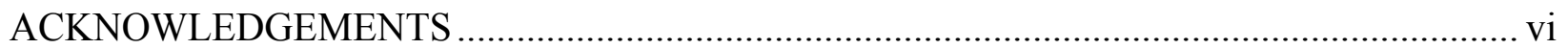

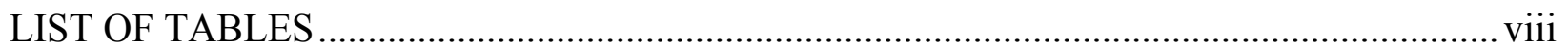

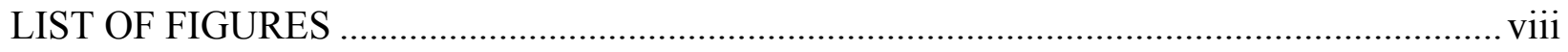

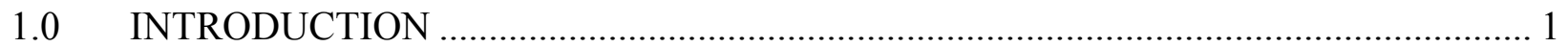

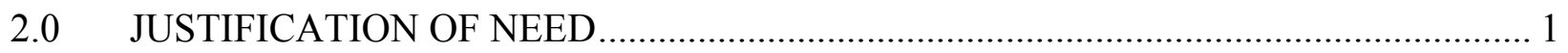

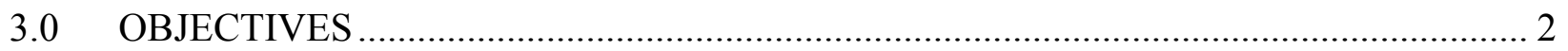

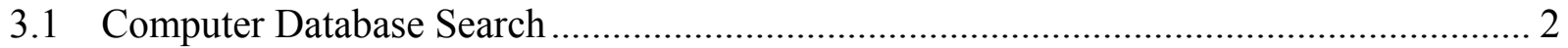

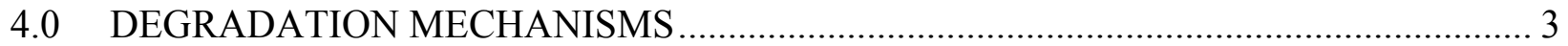

5.0 EVALUATION OF REFRIGERATION SYSTEMS ………........................................ 4

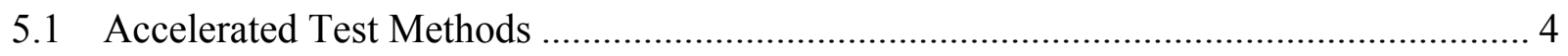

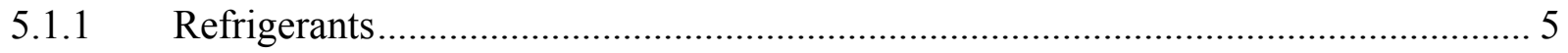

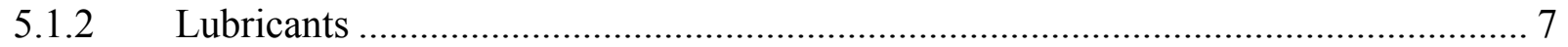

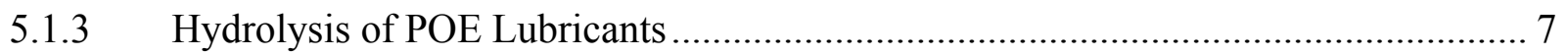

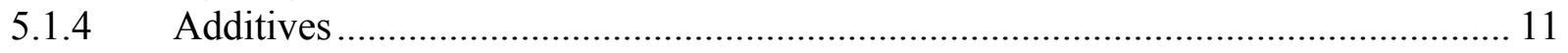

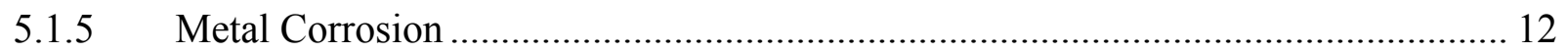

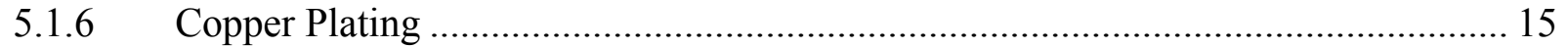

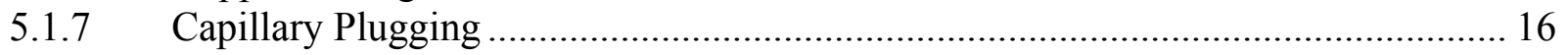

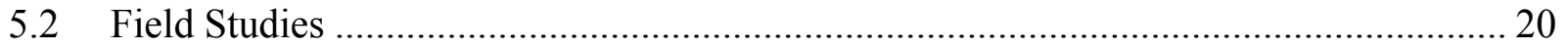

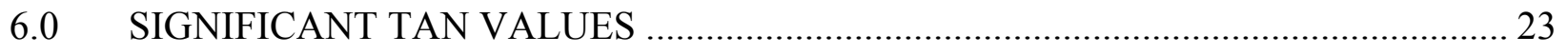

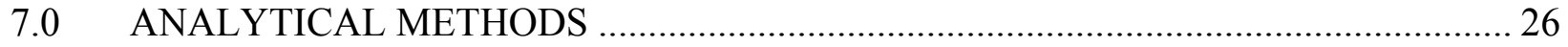

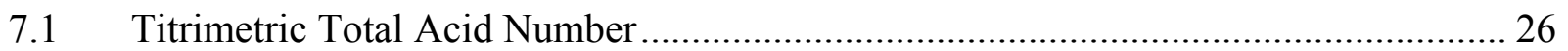

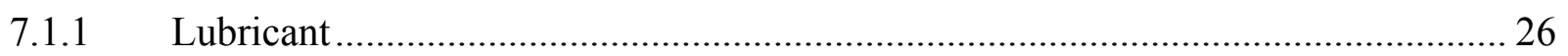

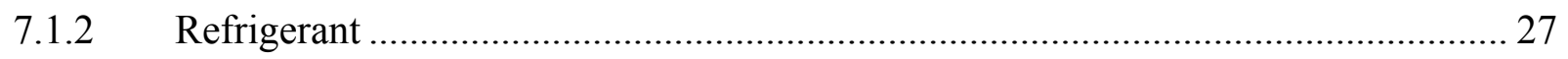

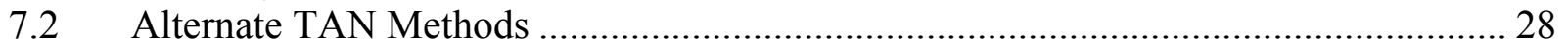

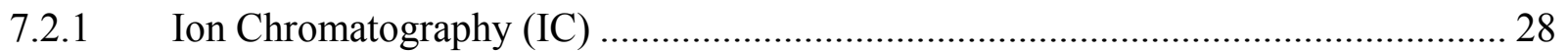

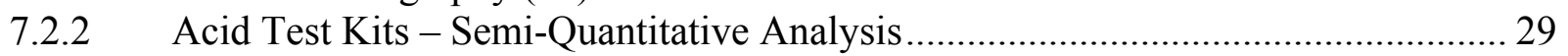

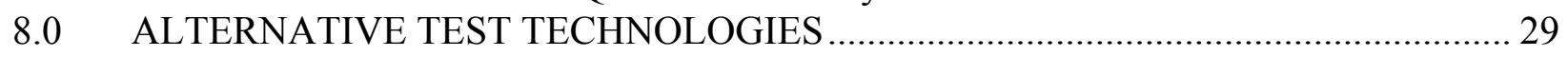

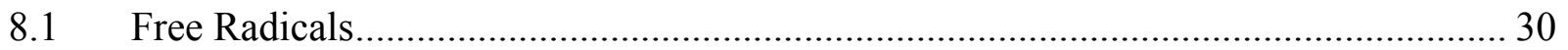

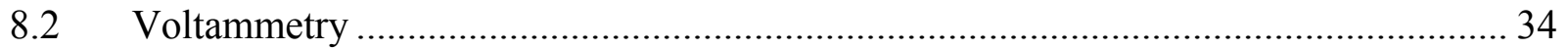

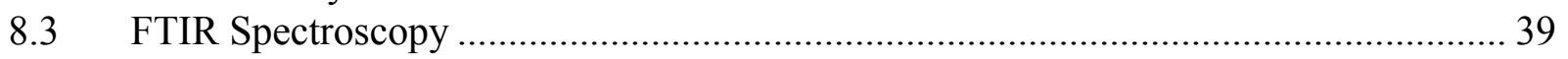

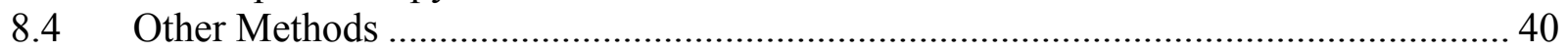

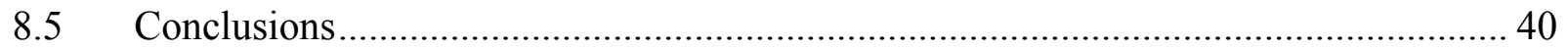

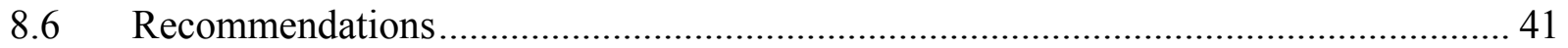

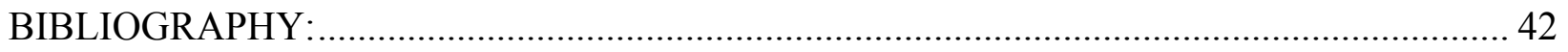

APPENDIX 1 Bibliography Synopses................................................................................. 49

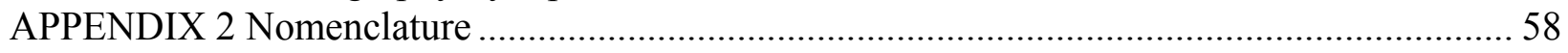




\section{LIST OF TABLES}

TABLE 1 Sealed Tube Tests of Contaminant Effects ........................................................... 15

TABLE 2 Capillary Tube Contaminants .............................................................................. 18

TABLE 3 Acidity Of Used CFC And HCFC Refrigerants And Lubricants............................. 21

TABLE 4 Correlation of RUL\% with RBOT and DSC Results............................................... 38

\section{LIST OF FIGURES}

Pigure 1. Pajor

Figure 2. Refrigerant Stability - Sealed Tube Tests ............................................................... 6

Figure 3. Effect of Water and Temperature on TAN in Sealed Tube Tests .............................. 8

Figure 4. Structures of Acids Used in POE Lubricants ...................................................... 9

Figure 5. Effect of Acid Structure on POE Hydrolytic Stability .......................................... 10

Figure 6. Effect of Acid Catcher on POE Hydrolytic Stability ............................................. 12

Figure 7. Reaction of POE with Contaminant Water or Hexanoic Acid ................................... 13

Figure 8. Reaction of POE Lubricant with Iron............................................................ 13

Figure 9. Lubricant Acid Number Distribution Probabilities in Normal vs Burnout

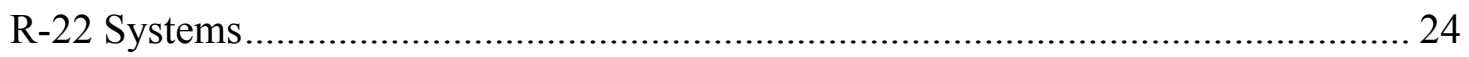

Figure 10. Oxidation Time vs Free Radicals, TAN and Particulates ..................................... 33

Figure 11: Factors Affecting Remaining Useful Life of Oil.................................................. 35

Figure 12: Portable RULER ${ }^{\circledR}$ Condition Monitoring Instrument ........................................... 36

Figure 13 Determination of Antioxidants by Cyclic Voltammetry ........................................ 37

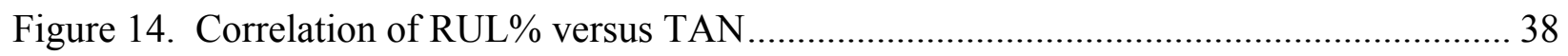




\subsection{INTRODUCTION}

Air conditioning and refrigeration equipment needs to provide long-term reliable use. It is important for engineers to design systems that maintain U.S. Department of Energy (DOE) mandated performance expectations to minimize energy usage, and, in turn, minimize $\mathrm{CO}_{2}$ emissions. In order to maintain high performance, the refrigerants and lubricants must not decompose significantly during their operation. Refrigerant and lubricant decomposition can produce acids that cause system components to wear and fail resulting in reduced system performance and higher energy use.

An ARTI-sponsored statistical study evaluated four refrigerants (R-22 as the main control versus R-134a, R-407C, and R-507A) and the effects of selected contaminants at levels that may be seen in new and retrofit systems (Cavestri et al. 2000). The presence of acids was positively related to corrosion effects on bearing surfaces and discharge valve components. The formation of water and acid was positively related to both refrigerant and lubricant degradation.

A major problem with polyol ester (POE) lubricants is their potential to revert to their basic molecular components of acids and alcohols. As a result of this reversal, polyol esters are capable of becoming acidic. The presence of organic acid can lead to the attack of metal components or other system materials leading to corrosion, compressor motor burn-out, excess wear, and poor lubrication of moving parts. The presence of acids can also cause secondary effects such as formation of salts; inorganic acids and sludge which in turn can themselves affect system performance. One example is that acid salts and sludges can plug or compromise expansion devices resulting in decreased system performance.

\subsection{JUSTIFICATION OF NEED}

Component and system cleanliness is a critical issue for hydrofluorocarbons (HFC) refrigerants and their attendant lubricants. These materials have greater solvency with manufacturing process fluids and residues causing these contaminants to migrate through the system more readily than previous refrigerants and lubricants. The migration process results in deposits at places of phase, temperature and pressure changes such as expansion devices leading to system malfunction.

The need exists for a single indicator to determine the relative health of a refrigeration system. This indicator would be key in keeping the refrigeration system running at or near optimum performance and could be used to signal when the system requires maintenance. Acid concentration is a key test used to quantify the levels of contaminants in a HFC system. It is currently difficult to identify, specify and quantify all the possible contaminants in a HFC system. Further studies are needed to define the point at which acid levels in HFC systems affect compressor reliability and system performance. Knowledge of the acid types formed and acceptable acid levels would enable manufacturers to recommend oil/refrigerant lifetimes and or 
oil/refrigerant change out guidelines. Currently, there are no established guidelines for polyol esters in the industry.

\subsection{OBJECTIVES}

The objectives of the project were:

1. Evaluate prior work regarding acid types and acid levels including both $\mathrm{CFC} / \mathrm{HCFC}$ historical data with mineral oil and/or alkyl benzene as well as HFC/POE systems.

2. Report on acid measuring techniques for non-aqueous systems in refrigeration and other industries.

3. Report on applicability of the techniques for measuring acid values over time in air conditioning and refrigeration systems.

4. Identify key areas requiring further investigation and important tasks in each area.

\subsection{Computer Database Search}

A computer database search was initially performed on major databases including the following:

- ARTI Refrigerant Database

- IIR Fridoc

- DOE Energy

Supplemental databases included:

- Chemical Abstracts

- Inspec (IEE, IEEE)

- Corrosion

- Pascal

- Engineering Index

- Current Contents and

- Lubrication Engineering (STLE)

A second mini-search of the databases was performed eight months later to update the survey to the present.

Keywords for the search included: acids, lubricants, refrigerants, hydrolysis, oxidation, degradation and analysis. 


\subsection{DEGRADATION MECHANISMS}

The degradation of refrigeration lubricants is a complex process involving acids and a variety of different types of chemical species, which interact with the acids or are formed as a result of the acids present. They include:

- Acids - involves both strong inorganic acids such as $\mathrm{HCl}$ and $\mathrm{HF}$ formed from the decomposition of refrigerants as well as weaker organic acids produced from decomposition or hydrolysis of the lubricants

- Water - reacts with polyol ester (POE) lubricants to form the parent organic acids and alcohols used to prepare the POE

- Metals - iron, aluminum, copper react with both inorganic and carboxylic acids to form salts or can catalyze hydrolysis reaction at higher temperatures

- Oxygen - the systems are hermetic but oxygen can be present due to incomplete evacuation or leaks or can possibly be produced from thermal degradation of oxygenated species such as POE within the system

- Free radicals - reactive intermediate degradation product

- Peroxides - reactive intermediate degradation product

- Ions $-\mathrm{F}^{-}, \mathrm{Cl}^{-}$formed as a result of refrigerant decomposition

- Additives - variety of different chemical types including antioxidants, metal deactivators, etc., can include nitrogen, sulfur, phosphate and phenolic compounds

- Particulates and sludges - wear metals and salts are formed which can cause plugging of the system

- Alcohols - formed by hydrolysis of polyesters, can act as solvent to carry degradation products throughout the system

- Polar compounds - decomposition products

The lubricant aging process may involve a number of different reactions, but the main process is the formation of increasing quantities of acids over time (Bartnikas 1994, Figure 1). The figure actually represents the oxidative degradation of petrocarbons. However many of the processes shown are common to the degradation of refrigeration lubricants. The initial formation of acids results in the dissolution of catalytic metals such as iron, copper and aluminum. At the same time, the interfacial tension, a measure of the sludging characteristics of the lubricant, decreases as the concentration of polar degradation products increases. Compounds such as antioxidants, which are added to stabilize some POE lubricants, also decrease over time. The concentration of free or unreacted acid gradually increases over a long period of time until a critical point is reached when the rate of acid formation increases exponentially. This rapid increase in acid then causes the formation of insoluble sludge, which can result in plugging of the system. One of the main objectives of this project is to determine a critical acid value, based on the literature data, where remedial action should be taken to avoid the onset of rapid acid formation and prevent detrimental effects on the compressor and system performance. 


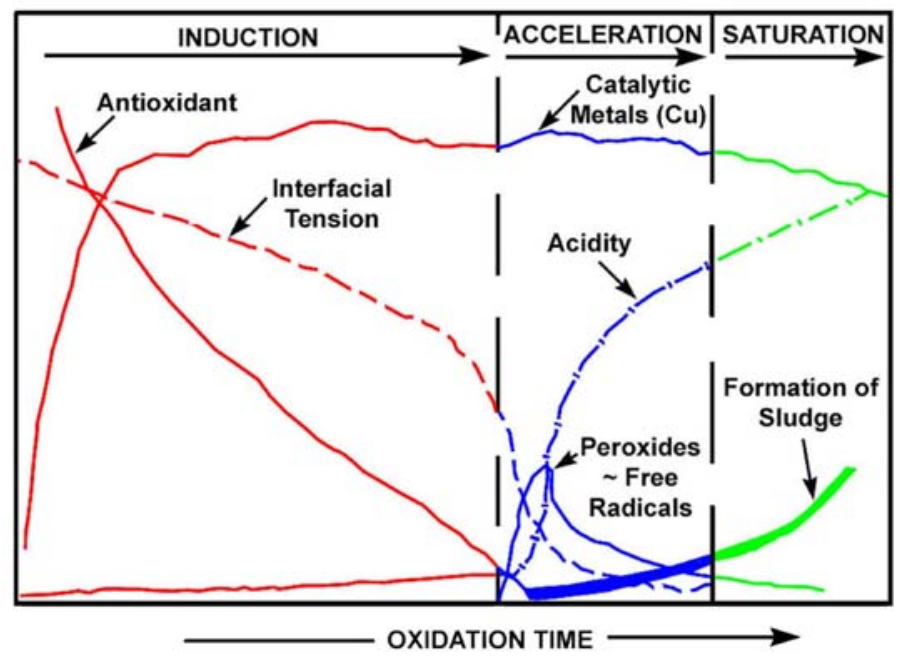

Figure 1. Major Processes of Lubricant Degradation

(Bartnikas 1994)

\subsection{EVALUATION OF REFRIGERATION SYSTEMS}

This section of the report, which discusses factors affecting the decomposition of refrigerants and lubricants, is divided into two parts. The first part discusses results that were obtained by laboratory accelerated aging tests (most of the literature references) whereas the second part deals with analyses of field samples.

\subsection{Accelerated Test Methods}

Accelerated test methods are used to evaluate materials in the refrigeration systems because the decomposition rate under normal operating conditions is very slow. Accelerated tests are very useful for screening and comparing different materials in a short time frame. However, one must be aware of the limitations of the data from accelerated tests. It is generally assumed that the degradation mechanism follows the Arrhenius rate equation but this may not always be the case, i.e., elevated temperature may result in a mechanism change. In addition, the mass ratio of the components in the accelerated tests may vary significantly from that found in real life.

The two types of accelerated test methods found most often in the literature search to investigate factors affecting refrigeration system acidity were the sealed tube test (ASHRAE Standard 971983) and system tests (ASHRAE 2002 Handbook on Refrigeration). The system fluids, reaction products and changes in the metals are analysed/examined following the aging period. In the first test method, sealed glass tubes containing refrigerant/lubricant mixture and metal coupons (usually aluminum [Al], copper $[\mathrm{Cu}]$ and iron [Fe]) are exposed to elevated temperatures for varying lengths of time. The test is very useful as a rapid screening tool but the 
results obtained tend to be greatly magnified because of the high exposure temperatures. In addition, since it simulates only the chemical aspects of the refrigeration system without consideration of the mechanical forces, the results obtained must be viewed very cautiously and be confirmed by alternate test methods. System tests involve both the chemical as well as the mechanical aspects of the refrigeration unit and include compressors, capillary tubes, etc. The results obtained from system tests more closely simulate real life conditions but the results must still be interpreted carefully since the tests are performed under severe operating conditions.

\subsubsection{Refrigerants}

There are significant differences in the system chemistry and the acidity characteristics of the older refrigeration systems employing $\mathrm{CFC} / \mathrm{HCFC}$ refrigerants with mineral oil compared to the newer systems using HFC refrigerants with POE lubricants. The major source of acidity in the older systems was the chlorinated refrigerants, which can thermally decompose at higher temperatures in the presence of metals such as $\mathrm{Al}, \mathrm{Fe}$ and $\mathrm{Cu}$ to produce strong inorganic acids - hydrochloric and hydrofluoric acids $(\mathrm{HCl}$ and $\mathrm{HF})$. This is a direct result of the relatively weak $\mathrm{C}-\mathrm{Cl}$ bonds $(78 \mathrm{kcal} / \mathrm{mole})$ in the $\mathrm{CFC}$ and HCFC refrigerants compared to the 93 and $100 \mathrm{kcal} / \mathrm{mole}$ strengths of carbonhydrogen and carbon-fluorine bonds, respectively in the newer refrigerants (Pauling 1960). As a result, HFCs are generally much more thermally stable than the chlorinecontaining refrigerants. This has been demonstrated in laboratory high temperature sealed tube tests, which determined the relative amounts of $\mathrm{Cl}^{-}$and $\mathrm{F}^{-}$produced from the thermal degradation of $\mathrm{CFC}, \mathrm{HCFC}$ and $\mathrm{HFC}$ refrigerants in the presence of steel (Huttenlocher 1992). The results (Figure 2) showed that HCFCs (R-22, R-124 and R142b) and HFCs (R-32, R-125, R-134, R-134a, R-143a and R-152a) combined with various lubricants (pentaerythritol [PE], polypropylene glycol [PPG], mineral oils [MOs], alkylbenzene $[\mathrm{AB}]$, polyol esters [POEs] and polyalkylene glycols [PAGs]) underwent significantly less refrigerant breakdown than CFCs (R-11 and R-12). 


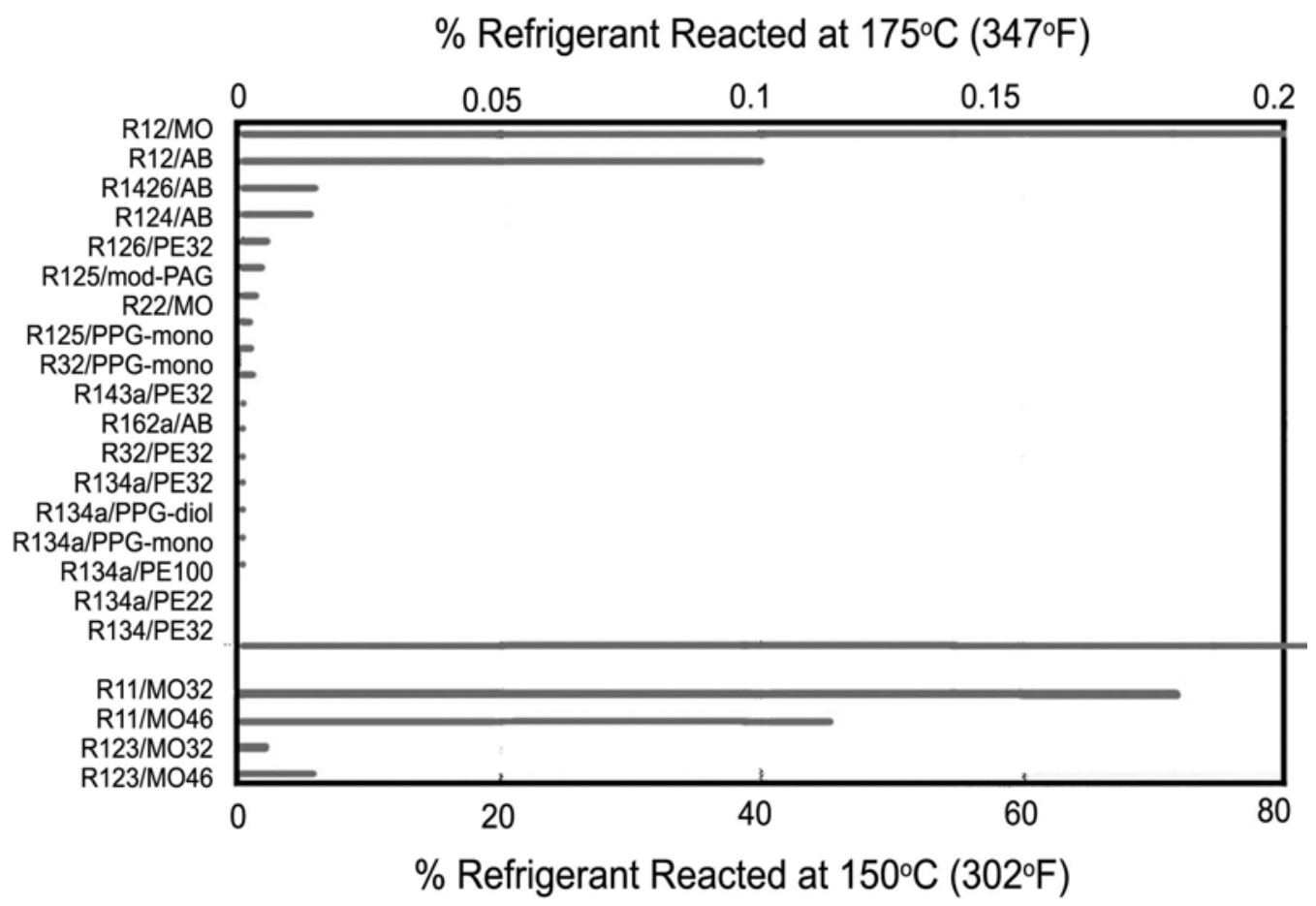

Figure 2. Refrigerant Stability - Sealed Tube Tests

(Huttenlocher 1992)

[Note: In figure 2, R1426/AB should be R142b/AB and R126/PE32 should be R125/PE32]

Field (1997) investigated corrosion using sealed tube tests at temperatures up to $200^{\circ} \mathrm{C}$ with R-134a refrigerant, POE lubricant and metal coupons in the presence of elevated levels of water and acid contaminants for periods up to 200 days. Gas chromatographic analysis of the refrigerants showed no changes in the refrigerant with any of the metals even under the most extreme conditions.

Refrigerant degradation under normal operating conditions is very small; however, the rate of thermal degradation reactions increases rapidly with increased operating temperature. In the case of chlorinated refrigerants, this can produce significant amounts of $\mathrm{HCl}$ and $\mathrm{HF}$, aggressive acids which can corrode the metals in the system to form sludge consisting of metal salts and deposits. The deposits can lead to flow restrictions in the narrower parts of the system such as expansion valves or capillary tubes and ultimately result in system failures. Some HFC degradation can occur at elevated temperatures but the amount of strong acid ( $\mathrm{HF}$ only) produced is minimal compared to the amount of $\mathrm{HCl}$ and $\mathrm{HF}$ produced from $\mathrm{CFC} / \mathrm{HCFC}$ refrigerants. However, additional strong acids can be generated in retrofitted HFC systems due to residual $\mathrm{CFC} / \mathrm{HCFC} /$ mineral oil carryover.

The degradation of CFCs to produce $\mathrm{HCl}$ has one positive aspect in that the iron chloride produced on wear surfaces acts as an excellent lubricity improver for the mineral oil lubricant to reduce sliding friction (Komatsuzaki and Homma 1991). The corresponding iron fluoride produced from HF does not have this capability and instead acts as a corrosive toward iron surfaces (Ishida 1996). Since HFCs are incapable of forming iron 
chloride to assist lubrication, it is sometimes necessary to incorporate extreme pressure additives such as phosphates into the POE or PAG lubricants to improve the lubrication properties (Komatsuzaki et al 1991, Vinci and Dick 1995).

\subsubsection{Lubricants}

Mineral oil and alkyl benzene lubricants are very stable compared to POE lubricants within a hermetically sealed refrigeration system. They are susceptible to thermooxidative degradation, particularly at higher temperatures if there is residual air in the system due to incomplete evacuation or development of a leak, which could result in the formation of low molecular weight carboxylic acids such as formic, acetic, etc. However, the acidity generated by the weak carboxylic acids from the lubricant degradation is insignificant compared to that produced by the strong acids, $\mathrm{HCl}$ and $\mathrm{HF}$, from the refrigerant decomposition. Mineral oil and alkylbenzene lubricants also have very low water solubility and are not susceptible to hydrolysis although the presence of water in excess of the saturation limit can lead to icing problems in expansion devices.

Polyol ester lubricants are noted for their superior high temperature resistance to thermooxidation over mineral hydrocarbons (Krevalis et al 1994). This has led to their wide spread use in automotive and turbine applications (Bakunin and Parenago 1992). However the newer lubricants suffer one major disadvantage compared to mineral hydrocarbons, namely their affinity for water. Polyol ester, polyvinyl ether (PVE) as well as the PAG lubricants used for automotive refrigeration applications are very hygroscopic having saturation values of 2,500,6500, and 10,000 ppm water, respectively, relative to mineral oil at $25 \mathrm{ppm}$ (Thomas and Pham 1989, Hiodoshi et al 1999). Due to their chemical structure, POE lubricants are also susceptible to hydrolysis (reverse esterification). When exposed to water and high temperature, these lubricants decompose to form organic acids and alcohols. As a result, POEs are the major sources of acidity in the HFC/POE refrigeration systems. The organic acids produced from hydrolysis, although much weaker than the mineral acids generated from CFC refrigerants, can further react with the system metals to produce carboxylic acid salts which can result in capillary tube plugging. In addition, the alcohol generated from hydrolysis may serve as a solvent to increase the distribution of contaminant throughout the system.

Although PAG and PVE have a greater affinity for water than POE, they are not susceptible to hydrolysis although they are prone to oxidative degradation (Komatsuzaki et al 1991, Hiodoshi et al 1999, Tominaga et al 2000). This decomposition process can also result in the generation of acidic by-products.

\subsubsection{Hydrolysis of POE Lubricants}

Hydrolytic decomposition of POE is actually a reversal of the esterification reaction used to produce the POE. The equilibrium can be represented by the following equation:

$\mathrm{RCOOR}+\mathrm{H}_{2} \mathrm{O} \Leftrightarrow \mathrm{RCOOH}+\mathrm{R}^{\prime} \mathrm{OH}$ Equ. 1 
The reaction rate of the pure reactants is very slow but the process is accelerated when catalyzed by the presence of acids, bases or metals and increases rapidly with increasing temperature. The amount of acid generated from POE hydrolysis is primarily dependent on the amount of water available since theoretically, one mole of acid will be generated for each mole of water that reacts with the lubricant. Because the hydrolysis reaction rate is rapidly accelerated with increasing temperature, the effects of increasing the water concentration on the TAN value can be readily seen using sealed tube tests at elevated temperatures (Figure 3). The hydrolysis rate increases rapidly at the early stages of the decomposition due to catalysis from the carboxylic acid generated and then gradually decreases as the water concentration is reduced. The reaction is not stoichiometric, since it is an equilibrium reaction, but most of the water present is consumed to form acid.

It is important to note that results obtained in these tests are magnified by the accelerated test conditions. Under normal service operating temperatures and moisture levels (100 $\mathrm{ppm}$ ), the hydrolysis reaction is very slow such that a significant increase in TAN would not be apparent except over a very long time period.

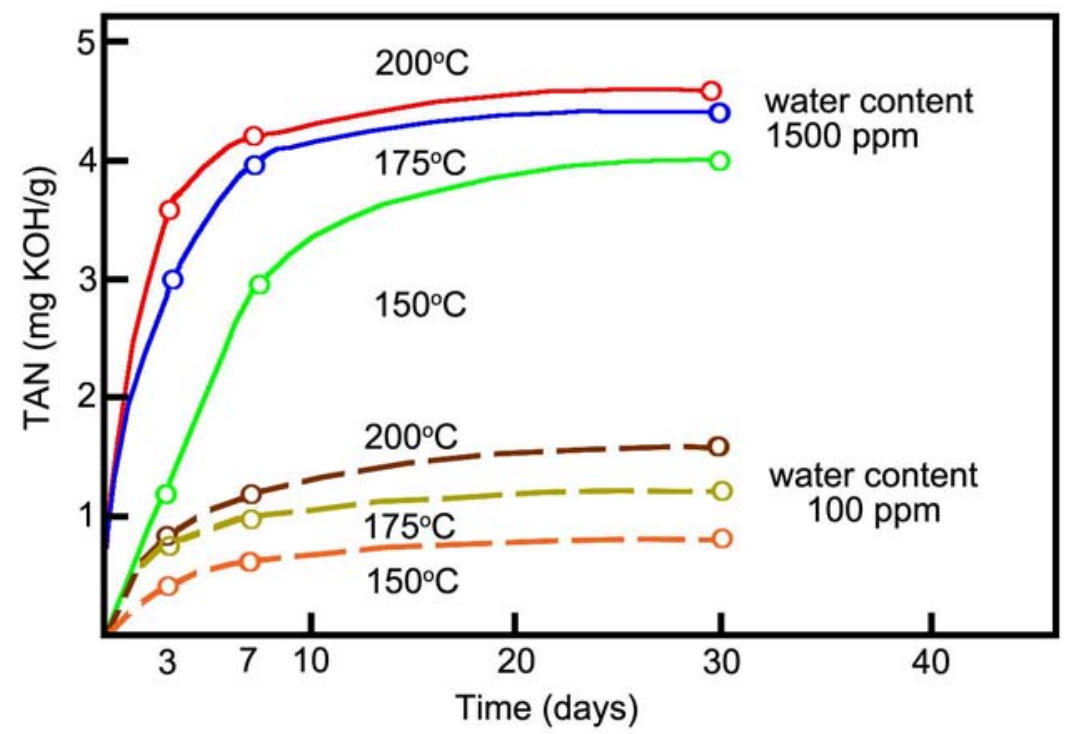

Figure 3. Effect of Water and Temperature on TAN in Sealed Tube Tests

(Takaichi and Sakai 1992)

It is important to maintain low moisture concentrations in POE systems to minimize the potential for hydrolysis. This is facilitated using a desiccant such as molecular sieve in an in-line drier (ASHRAE 2002 Handbook on Refrigeration). The function of the desiccant is not to remove all water from the system but to limit the amount of water to which the POE is exposed and thereby restrict the amount of acid produced. The effectiveness of a drier in maintaining low acid levels was demonstrated in extended compressor runs using R-134a refrigerant and POE lubricants with an initial moisture content of $\approx 50 \mathrm{ppm}$ (Hansen and Snitkjaer 1991). Acid levels reached TAN values exceeding $0.7 \mathrm{mg} \mathrm{KOH} / \mathrm{g}$ after 4000 hours when no drier was employed but averaged only $0.1 \mathrm{mg} \mathrm{KOH} / \mathrm{g}$ with a drier in place. In addition to limiting the exposure of POE to 
moisture, desiccants can also remove some of the acids (predominantly inorganic) present in the system (Cavestri and Schooley 1998).

The rate of acid formation from hydrolysis of refrigerant POEs and the resultant increase in TAN value is dependent primarily by the amount of water and temperature but is also affected by the chemical structure of the carboxylic acids used to prepare the POE. Typical types of carboxylic acids used to prepare refrigeration polyol esters and, which are ultimately the products of the hydrolysis, are shown in Figure 4. The chain length of the acid generally will range from five to ten carbons. Carboxylic acids are much weaker and less corrosive towards metals than $\mathrm{HCl}$ and $\mathrm{HF}$, however the lower molecular weight $\mathrm{C}_{1}-\mathrm{C}_{4}$ carboxylic acids are more corrosive than their higher molecular weight homologs. The upper carbon chain limit for the parent acids is restricted by the miscibility and viscosity properties of the product POE (Sunami et al 1994). Hydrolytic stability, as determined by increase in TAN value during sealed tube tests, showed that POEs containing longer acid chains and branched chain acids are more stable than those with linear acids.
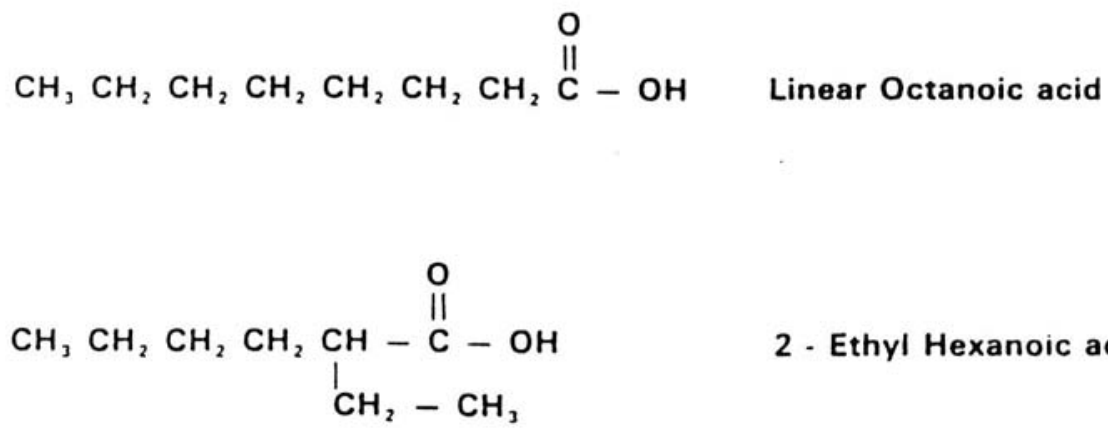

2 - Ethyl Hexanoic acid<smiles>CC(C)(C)C(=O)O</smiles>

Neo acids<smiles>CC(CC(=O)O)CC(C)(C)C</smiles>

3,5.5 - Trimethyl Hexanoic acid

Figure 4. Structures of Acids Used in POE Lubricants

(Tayler et al 1994)

Furthermore, since hydrolysis causes bond cleavage at the $\mathrm{O}-\mathrm{C}$ ester linkage, blockage of this location by using a branched acid at the $\alpha$ carbon position, i.e., a neo acid to form hydrolytically stable POEs (HSPOE) will further delay the hydrolysis reaction. Figure 5 shows the stabilizing effect of the hindered acid structure on TAN values in sealed tube tests at $175^{\circ} \mathrm{C}$ in the presence of 2000-ppm water (Sundaresan, 1997). With a conventional mixed-acid POE, the TAN value showed a noticeable increase from an 
initial value of $0.01 \mathrm{mg} \mathrm{KOH} / \mathrm{g}$ within a few days and then the rate of acid production increased sharply to a TAN value of 6 and then plateaued due to depletion of the water concentration. The hydrolysis reaction was suppressed with the hindered POE but would eventually reach the same TAN value as the mixed acid POE provided sufficient water was available.

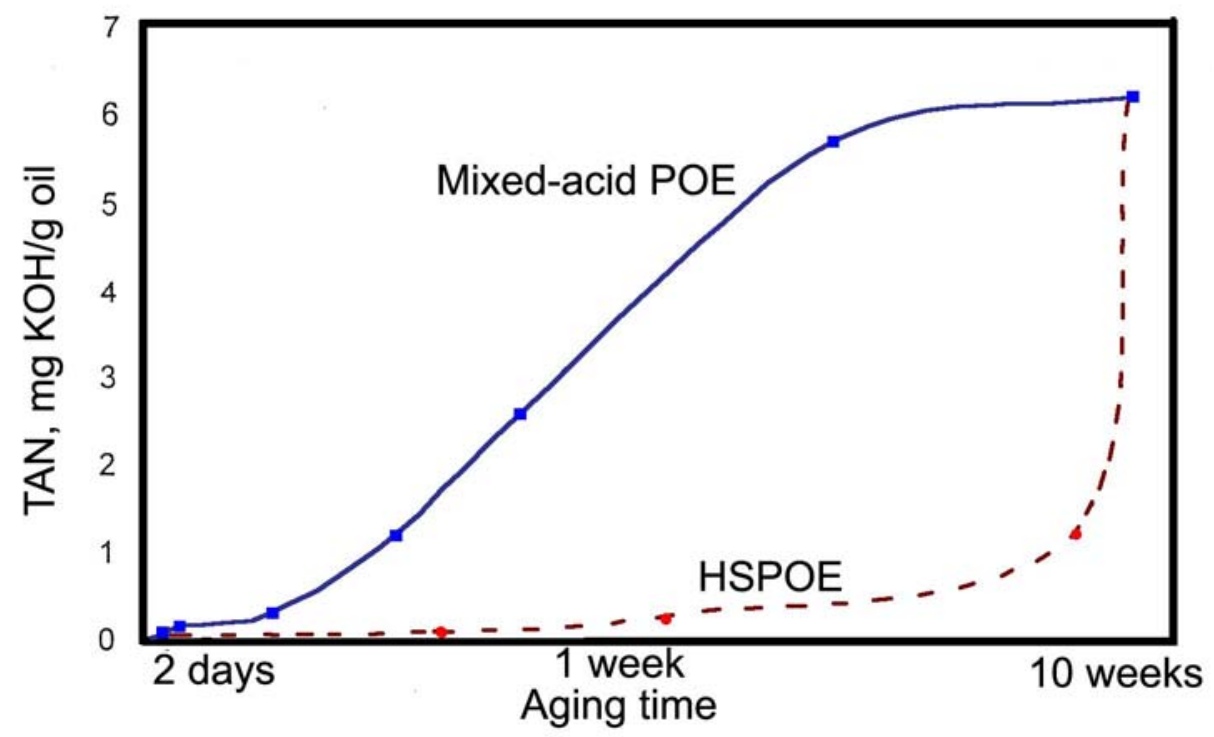

Figure 5. Effect of Acid Structure on POE Hydrolytic Stability

(Sundaresan 1997)

Refrigeration POEs are generally formulated using mono-functional organic acids with di-, tri- and tetrafunctional polyols. Shimomura et al (2000) reported that "new ester" lubricants formed from difunctional acids and monofunctional alcohol provided hydrolytic stability equivalent to that of branched POEs (based on sealed tube tests involving $500 \mathrm{ppm}$ water spikes) but also offered additional advantages.

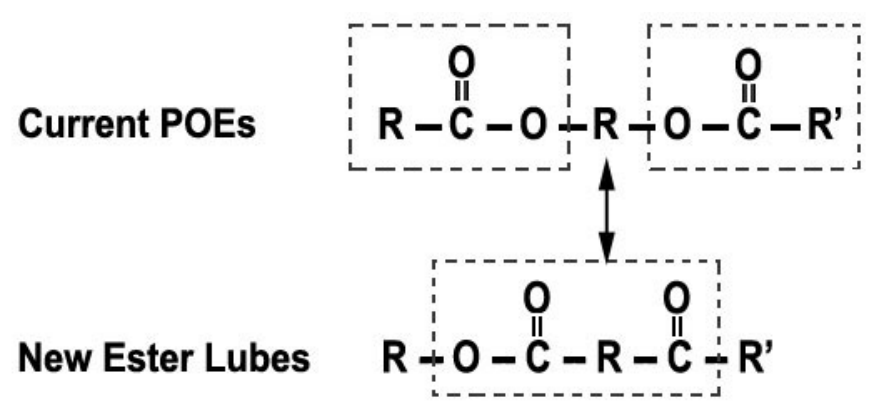

The corrosion characteristics of the new materials based on Falex tests were reported to be substantially lower than the POEs currently used. The solubility of system contaminants such as polybutene in the new esters was much improved relative to branched POEs and should therefore reduce the tendency for capillary plugging. 


\subsubsection{Additives}

The hydrolytic stability of POE lubricants can also be improved by additives, which either reduce the amount of acid present thereby minimizing catalytic effects, or reduce the amount of water available for the reaction, i.e. act as scavengers. The additives are usually epoxy derivatives but a number of different materials have been investigated (Takaichi and Sakai 1992, Vinci and Dick 1995, and Iizuka et al 1996). Finkenstadt and Mulay (2000) evaluated the effectiveness of an epoxy compound, neodecanoyl glycidyl ester, in retarding the POE hydrolysis using sealed tube tests at $150^{\circ} \mathrm{C}$ by addition of $1000 \mathrm{ppm}$ water and $1 \%$ "acid catcher" to three POEs. The progress of the reactions was followed by monitoring the reactants and the product acid and alcohol concentrations by GC-MS using trimethylsilyl derivatives. After 500 hours of aging, the acidity increased and then equilibrated at a TAN value of $\approx 3 \mathrm{mg} \mathrm{KOH} / \mathrm{g}$ for the control sample whereas the TAN value of the additive treated POE was unchanged at $<0.1 \mathrm{mg} \mathrm{KOH} / \mathrm{g}$ after 2000 hours. Since the additive functions by chemically reacting with acid and water and is consumed by the process, hydrolysis would eventually begin when the additive becomes depleted. Figure 6 shows the resulting TAN as a function of time in sealed tube studies at $130^{\circ} \mathrm{C}$ involving additions of $2000 \mathrm{ppm}$ water and varying concentrations of acid catcher (Boyde and Wilton 1999). At low concentrations, the additive was depleted more rapidly resulting in elevated TAN values. However, before using additives such as acid catchers at relatively high concentrations, it must be demonstrated that the reaction byproducts do not become a problem by precipitating and causing capillary plugging (Takaichi and Sakai 1992). The authors also cautioned that epoxy type acid catchers would negate the effectiveness of phosphate ester antiwear additives. However, Cavestri (1997) indicated that other types of acid catchers such as dialkylsulfides and phenylphosphite are compatible with the antiwear additives.

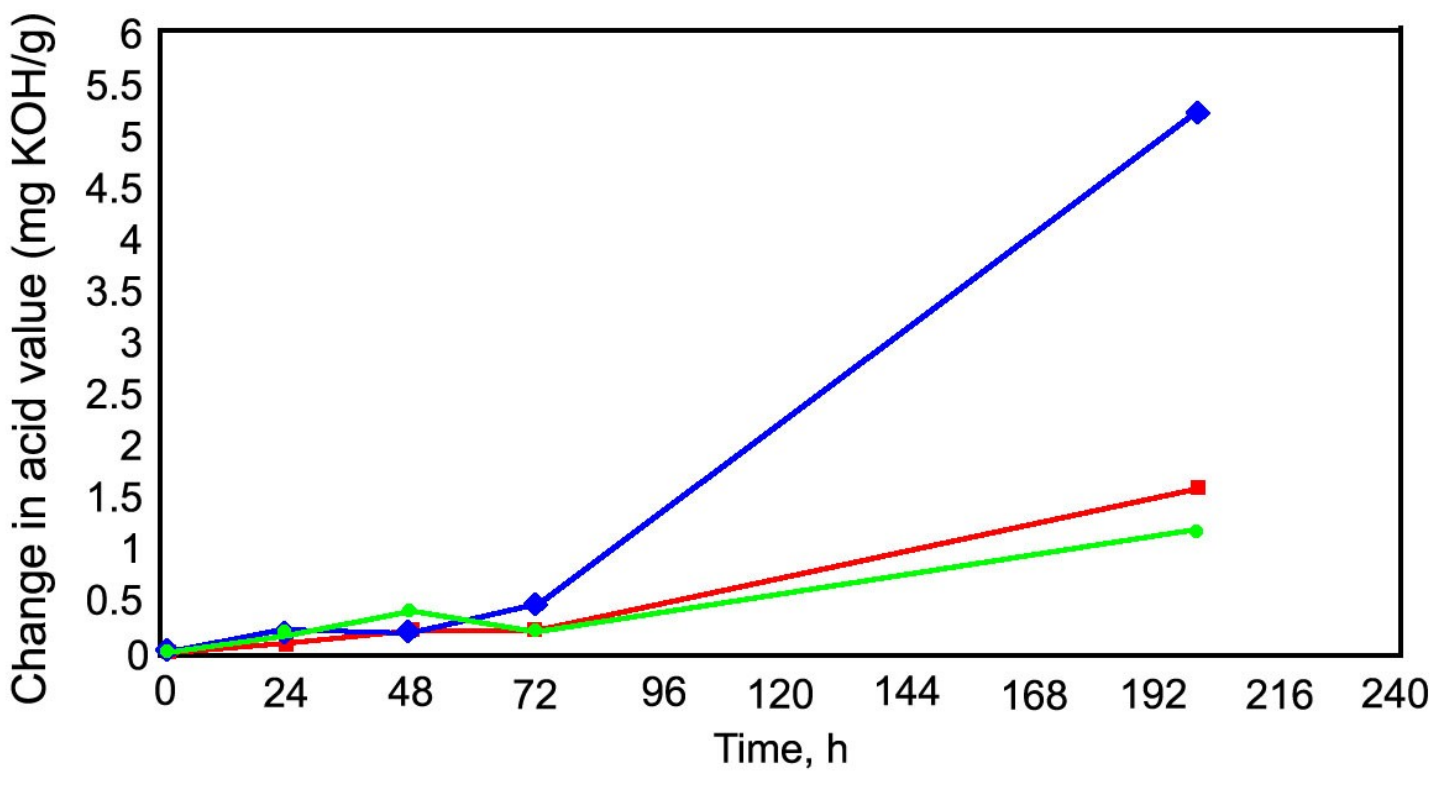

$\bullet 0.1 \%$ acid catcher $-0.3 \%$ acid catcher $\bullet 0.5 \%$ acid catcher 


\section{Figure 6. Effect of Acid Catcher on POE Hydrolytic Stability}

(Boyde and Wilton 1999)

A wide variety of additives are used in refrigerant systems to improve specific areas of refrigeration system performance however, as discussed above, care must be exercised to ensure that the additives do not impact adversely on other system chemistries (Vinci and Dick 1995).

Hydrolysis of POEs has been shown to be accelerated by the presence of acidic catalysts but some additives such as phosphate antiwear agents will preferentially hydrolyze to form acids and then promote accelerated decomposition of POEs (Tayler et al 1994, Sunami et al 1994).

Lilje (2000) examined the effect of various phosphorus antiwear additives on the hydrolysis of different POE lubricants in sealed tube teats with 2000 ppm added water. After one week of aging, samples with phosphate additives had TAN values of $\approx 6 \mathrm{mg}$ $\mathrm{KOH} / \mathrm{g}$ compared to $0.3 \mathrm{mg} \mathrm{KOH} / \mathrm{g}$ for the controls. This is likely due to the formation of strong mineral acid (phosphoric acid) from hydrolysis of the phosphates additives.

Cavestri and Schooley (1996) examined the compatibility of 64 process fluids used in the manufacture of compressors and other refrigeration components with R-134a and a POE lubricant. Acidity was determined following sealed tube tests at $175^{\circ} \mathrm{C}$ using $0.5 \%$ concentrations of the process fluids and $0.1 \%$ concentrations of dried residues in POE with steel coupons. The TAN values after aging were generally 4-5 times higher than that of the control $(0.04 \mathrm{mg} \mathrm{KOH} / \mathrm{g})$, however, several samples produced higher acidities and a few samples produced TAN values $>1$. It is therefore very important that the residual process chemical level should be as low as possible prior to operating the system to protect the POE lubricant.

\subsubsection{Metal Corrosion}

The effects of added water or acid (hexanoic acid) contaminants on the corrosion of individual metal coupons in contact with HFC R-134a and an additive-free branched acid POE lubricant were studied using sealed tube tests (Field 1997, Field and Henderson 1998). Aging temperatures of 150,175 and $200^{\circ} \mathrm{C}$ were used for aluminum, cast iron and steel samples whereas the copper, brass and steel/copper couples were aged at 125, 150 and $175^{\circ} \mathrm{C}$. The elevated temperature was selected for aluminum due to its low reactivity and for the cast iron and steel coupons due to application conditions experienced in actual systems. The results showed that the TAN values and the pentanoic acid produced from hydrolysis of the POE increased rapidly with increasing temperature and contaminant concentration and then leveled off due to depletion of the reactant water or acid (Figure 7). 


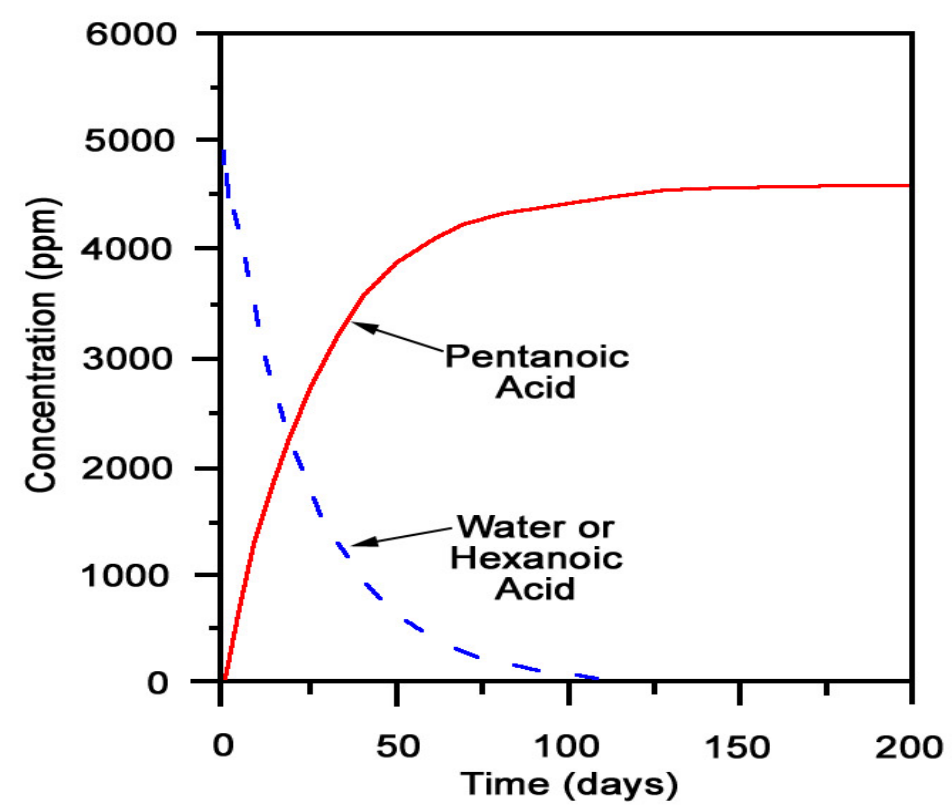

Figure 7. Reaction of POE with Contaminant Water or Hexanoic Acid (Field 1997)

The above scenario occurred with all of the non-ferrous metals but the decomposition reaction was much more vigorous in the presence of iron or steel particularly at higher temperatures. In these tests, the TAN/pentanoic acid concentrations did not level off but increased exponentially (Figure 8).

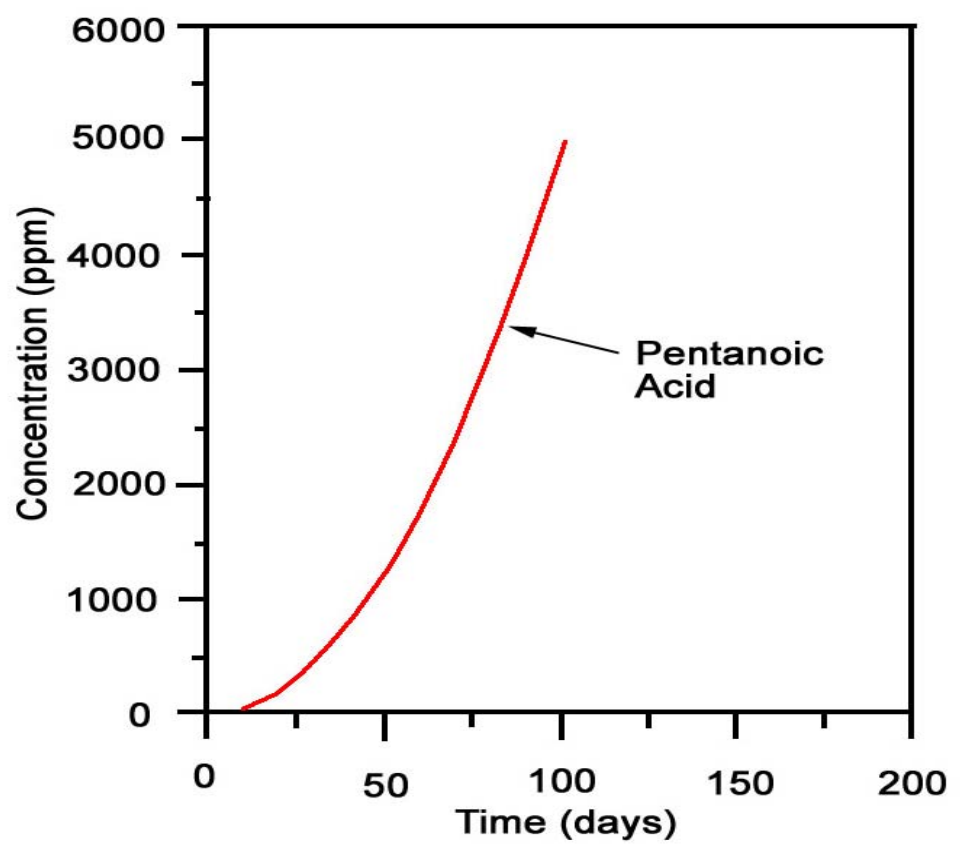

Figure 8. Reaction of POE Lubricant with Iron

(Field 1997) 
Medium amounts of precipitation were found at $175^{\circ} \mathrm{C}$ and heavy precipitation occurred at $200^{\circ} \mathrm{C}$. In contrast, little or no precipitation was observed with the non-ferrous metals.

One would expect the precipitate to be an iron carboxylate salt produced from the reaction of pentanoic acid with iron:

$2 \mathrm{C}_{4} \mathrm{H}_{9} \mathrm{COOH}+\mathrm{Fe} \Leftrightarrow\left(\mathrm{C}_{4} \mathrm{H}_{9} \mathrm{COOH}\right)_{2} \mathrm{Fe} \uparrow$ Equ. 2

However, no hydrogen gas was detected in gas chromatographic analyses of the vapor phase and examination of the precipitate by Fourier Transform Infrared Spectroscopy (FTIR) showed that only traces of carboxylic acid salt were present. The precipitate appeared to be predominantly iron oxides indicating that the reaction is an oxidation/reduction reaction such as:

$R C O O R^{\prime}+\mathrm{Fe} \Leftrightarrow R C O R^{\prime}+\mathrm{FeO}$ Equ. 3

Regardless of the chemical nature of the reaction product generated, the formation of an insoluble precipitate of any type can lead to problems. If sufficient material collects over time, plugging of narrower openings within the system such as capillary tubes can occur. This may ultimately result in system failure.

As would be expected based on the above results, the most severe corrosion was found with the coupons containing iron. Darkening was evident even in short exposures and, at the most extreme conditions involving high contaminant level and high temperature, large weight losses were experienced. Inductively Coupled Plasma Emission Spectroscopy (ICP) analysis of the lubricant showed dissolved iron concentrations exceeding $500 \mathrm{ppm}$ and large amounts of insoluble precipitate were formed particularly under the most severe reaction conditions. Scanning Electron Microscopy (SEM) examination showed significant surface corrosion and sufficient internal corrosion to cause structural degradation of the metal.

However, Lilje (2000) suggests that the amount of precipitate formed by this thermal degradation reaction with iron would be insignificant, if present at all, under actual service conditions since the activation energy required for the process would be extremely high. The reaction was predominant in the laboratory studies only under very high temperature conditions. These conditions are unlikely to occur in normally operated equipment except possibly under boundary lubrication conditions that would affect only a very small proportion of the lubricant.

Little change was evident in the surface finish and color of the copper coupons whereas the brass coupons changed to a dull pink color under moderate aging conditions and to a pink-brown color under severe aging conditions. The copper coupons exhibited very minor weight loss $(<1 \mathrm{mg})$ and dissolved copper (3 ppm) was only found with the coupons aged at $150^{\circ} \mathrm{C}$ with 5000-ppm hexanoic acid. No dissolved copper was found in 
the lubricant from the brass coupons, however low levels of zinc were found. An insoluble film was formed and traces of insoluble precipitate were found with both metals but there was insufficient material for identification. The copper coupons exhibited some surface corrosion and the brass coupons showed significant micro pitting on the surface but neither metal experienced internal corrosion.

Examination of the steel/copper joint material indicated that there was no interaction between the metals during the aging, i.e., each metal behaved independently. The steel became discolored and suffered surface corrosion and weight loss but there were no detectable changes in the copper or brass alloy. In addition, there was no evidence of copper plating on the steel. Elemental analysis showed dissolved metal content in the lubricant reached concentrations of up to $380 \mathrm{ppm}$ of iron and $21 \mathrm{ppm}$ zinc. A tan precipitate was produced similar to that formed with the aged steel samples.

Cavestri et al (2000) investigated the corrosive effects of organic acid, water and air contaminants in sealed tube tests at two temperatures as well as 12,000 hour compressor tests using R-507A containing 4\% R-502, R-407C containing 4\% R-22, R-134a containing 4\% R-12 and R-22 containing no refrigerant contaminant. A POE lubricant was used with the first three refrigerants whereas mineral oil was used with R-22. The sealed tube test results showed that low levels of organic acid and water both contributed to system corrosion but the degradation process was greatly accelerated in the presence of air. The amount of corrosion found with the POE systems was significantly less than that produced with the R-22 system.

TABLE 1

Sealed Tube Tests of Contaminant Effects

(Cavestri et al 2000)

\begin{tabular}{|c|c|c|}
\hline \multirow{2}{*}{$\begin{array}{c}\text { System } \\
\text { Refrigerant }\end{array}$} & \multicolumn{2}{|c|}{ System Temperature } \\
\hline & $135^{\circ} \mathrm{C}$ & $165^{\circ} \mathrm{C}$ \\
\hline$R-507 A$ & $\begin{array}{l}\text { - Acid corrodes copper in gas phase. } \\
\text { - Air generates precipitate. }\end{array}$ & $\begin{array}{l}\text { - Acid corrodes copper in gas phase } \\
\text { and corrodes valve steel. } \\
\text { - Air generates precipitate. }\end{array}$ \\
\hline $\mathrm{R}-407 \mathrm{C}$ & $\begin{array}{l}\text { - Air corrodes valve steel and generates } \\
\text { precipitate. } \\
\text { - Water, acid and R-22 corrode copper. }\end{array}$ & $\begin{array}{l}\text { - Air generates precipitate. } \\
\text { - Water, acid and R-22 corrode valve } \\
\text { steel. }\end{array}$ \\
\hline $\mathrm{R}-22$ & $\begin{array}{l}\text { - Air corrodes all metal and generates } \\
\text { precipitate. }\end{array}$ & $\begin{array}{l}\text { - Air corrodes all metals and } \\
\text { generates precipitate. }\end{array}$ \\
\hline$R-134 a$ & $\begin{array}{l}\text { - Water and acid corrode copper. } \\
\text { - Acid and air generate precipitate. }\end{array}$ & - Air generates precipitate. \\
\hline
\end{tabular}

\subsubsection{Copper Plating}

Chlorofluorocarbon/mineral oil refrigeration systems are prone to copper plating, i.e., the deposition of a copper film on hot steel surfaces of the compressor, e.g. bearings, which, under severe conditions, can cause impairment or even failure of the compressor. Both the mineral oil lubricant and the CFC refrigerant have been demonstrated to be factors in the process (Spauschus 1963), however the mechanism is still not fully understood. The process is thought to involve an initial oxidation of the copper followed by dissolution in the lubricant and finally deposition and reduction of the copper on iron surfaces. It has 
been suggested that the initiation stage is facilitated by system contaminants such as oxygen from entrained air, chlorinated materials from $\mathrm{CFC} /$ processing chemicals or by strong acids (Lilje 2000).

However, copper plating does not appear to be an issue with HFC/POE systems under normal conditions unless residual $\mathrm{CFC} /$ mineral oil is present. Sealed-tube aging studies involving $\mathrm{HFC} / \mathrm{POE}$ with metal coupons at temperatures up to $175^{\circ} \mathrm{C}$ for up to 199 days showed that the dissolved copper levels were low and that copper plating was not a problem with even with the addition of high concentrations of moisture or carboxylic acids (Field and Henderson 1998). Similarly, Lilje found no copper plating from the carboxylic acids generated by heating wet POE and metal coupons in sealed tubes at $150^{\circ} \mathrm{C}$ although the TAN values ranged from 1.05 to $7.5 \mathrm{mg} \mathrm{KOH} / \mathrm{g}$. However, copper plating was observed when $\mathrm{HCl}$ was added to the wet $\mathrm{POE}$ to raise the TAN value to 7.2 $\mathrm{mg} \mathrm{KOH} / \mathrm{g}$. Copper plating was also found in all cases where the sealed tubes contained R-22 with either wet POE or wet mineral oil, i.e., HCl was generated in situ (Lilje 2000). Cavestri et al (2000) investigated copper plating in compressors run for 12,000 hours using R-134a/POE containing 4\% R-12 and contaminated with organic acids, water and air and with R-22/mineral oil containing the same contaminant levels. The amount of copper plating on the internal compressor surfaces and the amount of chloride present in the lubricants were found to be similar. The level of copper plating was found to be independent of the contaminant levels.

An R-134a/PAG mixture produced relatively small amounts of copper plating compared to that generated by a R-12/mineral oil system in sealed-tube aging tests performed at $65^{\circ} \mathrm{C}$ for up to four months (Thomas and Pham 1989). Increasing the moisture content to $5,000 \mathrm{ppm}$ did not have any apparent effect on the amount of copper produced. However, in the presence of contaminants such as air, CFC or aged mineral oil, R-134a/PAG mixture, the amount of copper plating was significantly increased (Suva Refrigerants Technical Bulletin 1992).

A survey of Danish refrigeration and heat pump consultants responsible for conversion of 20,000 plants from CFC to HFC refrigerants indicated that copper plating in the converted system could be avoided provided that the residual mineral oil level was $<1 \%$ and the moisture content was less than 50 ppm (Herbe and Lundqvist 1997).

\subsubsection{Capillary Plugging}

Tazaki et al (1997) suggest that capillary tube plugging is more predominant in $\mathrm{HFC} / \mathrm{POE}$ systems than in the older CFC/mineral oil systems due to the reduced solvency characteristics of the new refrigerants and lubricants. Organic chemical residues from the system components are less soluble in HFCs than in the chlorinated CFC or HCFC refrigerants and therefore tend to precipitate out at the lower temperature at the capillary tube or expansion valve. Similarly, processing chemicals such as cutting, washing and rust preventative oils are less soluble in oxygenated synthetic lubricants such as POE or PVE and tend to precipitate on the inner capillary walls.

Tayler et al (1994) reported that capillary tube blockage in POE systems is due to three main mechanisms which involve the gradual deposition of: 
- Resinous Materials

These are predominantly PET (polyethylene terephthalate) oligomers from the compressor motor insulation and fines from the molecular sieve dryer

- Chemical/Physical Reaction Products

These include lubricant decomposition products such as carboxylates, additive decomposition products (metal chlorides, phosphates, sulphides, etc.), corrosion deposits, and tribological debris from sliding surfaces

- System Contaminants

These include mineral processing oils and lubricants, brazing fluxes, silicone oils and flushing solvents (can contain chlorinated materials) from construction of the refrigeration unit

The authors suggested that capillary tube blockage occurs mainly as a result of an accumulation of a primary contributor which then acts as an attractor for the other materials including resins, decomposition products and debris which adhere to the primary layer and gradually buildup to form a blockage. In many cases the primary attractor is hydrocarbon-processing fluids but can include paraffin wax from the motor winding operation. In Europe, the trend is to replace the hydrocarbon processing fluids with equivalent ester products, which would have a much higher solubility in the POE refrigerant lubricants.

lizuka et al (1996) suggested that capillary tube plugging can arise from a number of potential sources including:

- Compressor

- Refrigeration Cycle $\quad$-molecular sieve powder from drier

- polybutylene from capillary tube drawing oil

- flux from brazed connection

- air, moisture, dirt, from contaminant filter

High temperature continuous or intermittent compressor tests were performed to evaluate capillary plugging with R-134a/POE. The deposits formed at different locations of the capillary were extracted and then analysed by Fourier Transform Infrared Microscopy (FTIR-M) and Gas Chromatography-Mass Spectroscopy (GC-MS). The amounts of deposit and the compositional makeup varied depending on location: 
TABLE 2

Capillary Tube Contaminants

(lizuka et al 1996)

\begin{tabular}{|c|l|c|c|c|c|c|c|}
\hline \multirow{2}{*}{ Test } & \multicolumn{1}{|c|}{$\begin{array}{c}\text { Deposit } \\
\text { Location }\end{array}$} & $\begin{array}{c}\text { Sludge } \\
\text { Quantity }\end{array}$ & $\begin{array}{c}\text { Hydro } \\
\text { carbon }\end{array}$ & $\begin{array}{c}\text { Metal } \\
\text { Carboxylate }\end{array}$ & $\begin{array}{c}\text { Organic } \\
\text { Silicone }\end{array}$ & $\begin{array}{c}\text { Petroleum } \\
\text { Sulfonate }\end{array}$ & $\begin{array}{c}\text { Poly- } \\
\text { butylene }\end{array}$ \\
\hline \multirow{3}{*}{$\begin{array}{l}\text { Continuous } \\
\text { Operation }\end{array}$} & Inlet & + & weak & mid. & W- mid & weak & - \\
\cline { 2 - 8 } & Outlet & + & strong & w-mid & weak & mid. & - \\
\cline { 2 - 8 } & $\begin{array}{l}\text { Connecting } \\
\text { Tube }\end{array}$ & ++ & strong & Strong & mid. & - & - \\
\hline \multirow{3}{*}{$\begin{array}{l}\text { Intermittent } \\
\text { Operation }\end{array}$} & Inlet & ++ & mid. & mid & - & - & strong \\
\cline { 2 - 8 } & Outlet & trace & - & - & - & - & - \\
\cline { 2 - 8 } & $\begin{array}{l}\text { Connecting } \\
\text { Tube }\end{array}$ & trace & - & - & - & - & - \\
\hline
\end{tabular}

The authors suggest that the carboxylate salt found in the capillary deposits is the end result of acids produced via three different POE decomposition mechanisms, or combinations thereof, depending on the temperature at different locations within the system and the presence of other contaminants:

- Pyrolysis

- occurs at temperatures $>200^{\circ} \mathrm{C}$ with little or no oxygen present

- occurs in areas of boundary lubrication

- products include acids + hydrocarbons

- Oxidation

- occurs at temperatures $<150^{\circ} \mathrm{C}$ in the presence of oxygen

- can be minimized by use of antioxidant in the oil

- products include acids + polymeric materials

- Hydrolysis

- occurs at temperatures $>90^{\circ} \mathrm{C}$ in the presence of water

- can be minimized by use of molecular sieve drier and acid catcher compounds

- products include acids + alcohols

The problem is exacerbated by the reaction of the acids generated from the three degradation processes with corrosive wear particles from the system to form sludge, which ultimately can result in blockage of the capillary tube.

There was no change in the TAN values following the runs, i.e., $\leq 0.03 \mathrm{mg} \mathrm{KOH} / \mathrm{g}$ with a free fatty acid content of $<10 \mathrm{ppm}$, however, the POE oil contained an "acid catcher" additive which would prevent acid buildup. The acid catcher concentration was not disclosed but the consumption ranged from $35-94 \%$ during the tests.

DeVos (1997) investigated the effect of added contaminants such as organic chloride $(50-500 \mathrm{ppm})$ and moisture $(100-500 \mathrm{ppm})$ in R-134a/POE system tests on capillary tube blockage for periods up to 9 months. Elevated levels of either contaminant were reported to result in decreases in capillary flow. The deposits causing the flow reductions were found to consist of the added chlorides as well as ester breakdown products and carboxylate salts. Additional tests conducted at increased operating temperatures resulted in much more significant capillary flow reductions (up to 39\%) after 30 days of 
testing. Infrared analyses of the deposits formed at the capillary inlet showed that the material was composed of carboxylate salts. Traces of decomposed polyester oil were also identified on the capillary outlet.

Analysis of the POE lubricants from three of the units subjected to the higher temperature runs showed that the TAN values $(\leq 0.03 \mathrm{mg} \mathrm{KOH} / \mathrm{g})$ were relatively unaffected by the accelerated aging indicating that the main POE decomposition process was likely due to thermal degradation. Metal analysis of the lubricants showed small but measurable amounts of dissolved iron, silicon, boron and phosphorus. Brazing flux was thought to be the source of the boron whereas the other materials were attributed to either compressor wear during the test or machining operations during the compressor/heat exchanger manufacturing processes. One of the three POE samples was black, as opposed to the normal yellow color, and was found to contain large amounts of aluminum. Further analysis showed that the compressor used with this sample exhibited abnormal wear in a temperature sensitive region.

Tazaki et al (1997) also examined the effect of contaminants on capillary tube blockage in systems using R-134a refrigerant and either a polyolester or a polyvinyl ether lubricant. Both types of lubricants are hygroscopic, however, because of its chemical structure, PVE does not hydrolyze to form carboxylic acids which can then form metallic salts.

The contaminants used for the study were obtained by rinsing brand-new refrigeration parts, including heat exchanger and compressor motor components, with solvent. Three per cent of the isolated contaminants were added to the lubricants and the performance in laboratory test stands was monitored until the suction pressure was $<0.1 \mathrm{MPa}$. Blockage occurred in the POE units after $\approx 700$ hours whereas the PVE units ran for $1200-1300$ hours before plugging. The difference in longevity was attributed to the lower solubility of the contaminants in the POE oil compared to the PVE lubricant.

Contaminants isolated from the new parts consisted of mineral oil (mainly $\mathrm{C}_{4}-\alpha$-olefin polybutene), dioctylphthalate (a common plasticizer) and aliphatic carboxylate material, mainly $\mathrm{C}_{12}-\mathrm{C}_{18}$ (possibly a rust preventative additive in the form of a wax metallic salt). The deposits found in the capillary blockages had very similar composition to the above but also contained an extreme pressure PVE additive and inorganic salts $\left(\mathrm{CuCl}_{2}\right.$ and $\mathrm{Cu}_{2} \mathrm{O}$ ). There was no mention of carboxylates originating from the POE lubricant in the deposit; however, the run times were relatively short.

The capillary plugging characteristics and wear potential of residential air conditioning R-410 systems using alkylbenzene or POE lubricants were compared to that of R-22 with a mineral oil lubricant in durability tests performed by operating rotary compressors under overload conditions (Sekiya et al 1998). The flow reductions observed in both the POE and mineral oil lubricant systems exceeded 10\% after 4000 hours whereas flow reductions in the alkyl benzene system were less than 5\%. Examination of the capillary tubes in the alkylbenzene equipped systems showed minimal amounts of sludge (nonchlorine containing inorganics) compared to that found in the systems using POE or mineral oil (metallic soap, i.e., carboxylate or metallic chlorides respectively) The wear volumes on the vanes and rolling pistons were found to be much greater for the R-22/mineral oil than for either of the alkylbenzene or POE lubricants. 
Sato et al (1998) performed more detailed analysis of two different capillary deposits obtained from 2000-hour runs using R-407C and a polyolester lubricant in systems equipped with scroll compressors. The first deposit was obtained from runs in which 1000 ppm water and an extreme pressure additive, triphenylphosphate (TPP), were added to the system. The second deposit was collected from the capillary after runs in which there were no additions of water or TPP. The deposits were solvent extracted and analyzed using FTIR, GC-MS and X-ray. Both deposits contained ester oil products but the first deposit also contained iron phosphoric acid salt oligomers of terephthalic acid, palmitic acid, etc. derived from esters. The second deposit contained metal carboxylate salts, predominantly iron. The authors suggest a mechanism involving iron hydroxide for the formation of the iron carboxylate.

Much of the problem with capillary plugging in POE systems appears to be due to the poor solubility of process contaminants in POE. Shimomura et al (2000) performed precipitation tests on a conventional branched POE and new type of POE, produced by reacting a dicarboxylic acid and a monofunctional alcohol, using polybutene, a predominant system contaminant, as the solute. The solubility was much better in the new POE, which should minimize capillary plugging.

\subsection{Field Studies}

Despite the abundance of publications involving accelerated aging tests of lubricants involving sealed tubes, relatively few references were found which examine the behavior of lubricants in field situations particularly those involving system failures. As a result, it was not possible to set up a relational database of field variables. While the sealed tube test is an excellent tool for comparative analysis or screening of additives, the results obtained do not readily translate into expected behavior under field conditions.

Kauffman (1990) examined the contaminant levels in used CFC and HCFC refrigerants and lubricants obtained from normally operating systems and failed refrigerating and air conditioning systems which had been in operation for periods ranging from a few months to 27 years. The R-11 samples were taken from 200 to 504 ton systems regardless of required service whereas the samples from R-12 commercial refrigerators, R-22 heat pumps and air conditioners and R-502 frozen food cases were obtained from systems containing compressors ranging from 1 to $10 \mathrm{hp}$ in which system malfunctions, including motor burnouts, had occurred.

The acid levels in the R-11 systems increased from an initial value of $0.0005 \mathrm{mg} \mathrm{KOH} / \mathrm{g}$ to an average value of $0.02 \mathrm{mg} \mathrm{KOH} / \mathrm{g}$ (Table 3). In most of the refrigerant samples, organic acids were the predominant species over the mineral acids - mainly $\mathrm{HCl}$. The situation was reversed in the oil samples where hydrochloric acid concentrations always exceeded the organic acid concentration. The acid levels in the oil samples appeared to increase with operating time whereas this trend was not evident in the refrigerant acids. 
The acidities of the R-12 refrigerant samples were very low $(<0.003 \mathrm{mg} \mathrm{KOH} / \mathrm{g})$ and were due entirely to organic acids. The levels did not correlate with the type of system or the operating time. The lubricant acidity was also entirely organic in nature but higher levels were found ranging from 0.02 to $0.14 \mathrm{mg} \mathrm{KOH} / \mathrm{g}$ of lubricant in the normal systems. The refrigerant from the failed systems also exhibited low acidity but the lubricant acidity in one system was relatively high at $0.8 \mathrm{mg} \mathrm{KOH} / \mathrm{g}$ and was mainly due to equivalent amounts of $\mathrm{HCl}$ and $\mathrm{HF}$ rather than organic acids.

The used R-22 refrigerant acid levels were barely detectable at $0.0005 \mathrm{mg} \mathrm{KOH} / \mathrm{g}$ but the acid levels in refrigerants from the burnout samples were much higher with an average value of 0.11 $\mathrm{mg} \mathrm{KOH} / \mathrm{g}$. Hydrochloric acid was the major acidic component in five of the burnout refrigerant samples whereas HF predominated in the remaining two samples. The acid levels in the used R22 compressor oil samples averaged $0.04 \mathrm{mg} \mathrm{KOH} / \mathrm{g}$ of organic acids compared to $0.38 \mathrm{mg}$ $\mathrm{KOH} / \mathrm{g}$ for the burnout samples which contained both organic as well as mineral acids.

The used R-502 refrigerant samples contained an average of $0.004 \mathrm{mg} \mathrm{KOH} / \mathrm{g}$ of organic acids whereas the $0.014 \mathrm{mg} \mathrm{KOH} / \mathrm{g}$ acidity of the single burnout refrigerant sample was predominantly mineral acid - mainly $\mathrm{HCl}$. The used R-502 oil samples contained an average of $0.05 \mathrm{mg} \mathrm{KOH} / \mathrm{g}$ of organic acids. Organic acids were also predominant in the oil of the single burnout sample accounting for $2 / 3$ of the total acid content. Hydrochloric acid was found to be the major mineral acid present.

TABLE 3

Acidity Of Used CFC And HCFC Refrigerants And Lubricants

(Kauffman 1990)

\begin{tabular}{|c|c|c|c|c|c|}
\hline \multirow{2}{*}{ Refrigerant } & \multirow{2}{*}{$\begin{array}{c}\text { Number of } \\
\text { Samples }\end{array}$} & \multicolumn{2}{|c|}{$\begin{array}{c}\text { Acidity of Refrigerant } \\
\text { (mg KOH/g) }\end{array}$} & \multicolumn{2}{c|}{$\begin{array}{c}\text { Acidity of Oil } \\
\text { (mg KOH/g) }\end{array}$} \\
\cline { 3 - 6 } & & Total & Mineral & Total & Mineral \\
\cline { 3 - 6 } & 10 & $0.01-0.05$ & $<0.01$ & $0.04-0.14$ & $0.02-0.11$ \\
\hline R-11 & & & & & \\
\hline R-12 & 5 & $<0.003$ & $<0.0005$ & $0.02-0.14$ & $<0.0005$ \\
\hline Normal & 2 & $<0.0008$ & $<0.0005$ & $0.8^{*}$ & $0.6^{*}$ \\
\hline Burnout & & & & & \\
\hline R-22 & 8 & $<0.0005$ & $<0.0005$ & $0.02-0.10$ & $<0.0005$ \\
\hline Normal & 7 & $0.01-0.36$ & $0.01-0.31$ & $0.07-1.31$ & $0.02-1.10$ \\
\hline Burnout & & & & & \\
\hline R-502 & 6 & $<0.0005-0.1$ & $<0.0005$ & $0.02-0.08$ & $<0.0005$ \\
\hline Normal & 1 & 0.014 & 0.01 & 0.10 & 0.03 \\
\hline Burnout & & &
\end{tabular}

*one sample analysed

The average moisture contents of the used oil lubricants ranged from 19 to $47 \mathrm{ppm}$ compared to initial values of 9 to $12 \mathrm{ppm}$. The moisture contents of the R-12, R-22 and R-502 lubricants appeared to be independent of the systems or the years of service. The R-11 lubricants of units with 6 or less years of service ranged from 12 to $16 \mathrm{ppm}$ whereas those in service for 13 to 27 years ranged from 22 to $38 \mathrm{ppm}$. 
The levels of refrigerant particulates, which included $\mathrm{Al}, \mathrm{Cu}, \mathrm{Fe}, \mathrm{Pb}, \mathrm{Si}, \mathrm{Sn}$ and $\mathrm{Zn}$ ranged from 1 to $88 \mathrm{ppm}$ and were dependent on the service history of the units. The low particulate counts found in the non-burnout samples consisted of smooth platelets containing Fe with minimal amounts of $\mathrm{Cl}$ and were produced from worn compressors containing oils with low levels of mineral acids. The burnout unit samples contained higher particulate levels which consisted of rough metal chloride particles produced from compressors containing much higher levels of mineral acids in the oil.

A Danish study compared seven apartment refrigerators equipped with R-134a and a linear ISO 17 POE oil versus three units containing R-12 and a 100\% naphthenic based mineral oil after five years operation (Riemer and Hanson 1996). The TAN values for the POE ranged from $0.051-0.066 \mathrm{mg} \mathrm{KOH} / \mathrm{g}$ from an initial value of 0.041 whereas the mineral oil TAN values were unchanged at $0.021 \mathrm{mg} \mathrm{KOH} / \mathrm{g}$. The moisture contents of two of the POE samples were 50 ppm or higher and the remaining samples were $<40 \mathrm{ppm}$ whereas the moisture contents of the mineral oils were less than the $35 \mathrm{ppm}$ initial value. The molecular sieve driers for the R-134a and R-12 contained 0.194 and $0.117 \mathrm{~g}$ water respectively. The increased level in the R-134a driers was attributed to the higher initial moisture content of the POE. Gas chromatographic analyses of the refrigerants indicated negligible degradation had occurred within the five years. Examination of the capillary tubes for the R-12 systems showed that flow reduction was $<2 \%$ for all units whereas 11/14 POE tubes had flow reductions of $<2 \%$. The flow reductions were $<3 \%$ for two of the POE tubes and one had a flow reduction of $9 \%$. The precipitated material in the three POE capillary tubes was identified as an internal lubricant from a plastic part within the compressor. The authors stated that extensive testing indicated that this material would not cause major problems in the capillary tubes and that the internal lubricant is no longer used in the manufacture of plastic compressor parts. Examination of compressor parts following dissection and disassembly showed that no severe wear or copper plating had occurred in any of the units.

Herbe and Lundqvist (1997) investigated the effect of acidity, moisture and residual mineral oil in retrofitted refrigeration and heat pump plants, predominantly those which had been converted from R-12 to R-134a. A database was established which included TAN, moisture content and dissolved metal results from the analyses of 600 lubricant samples obtained from the retrofitted plants before and after the conversion. The documentation also included pertinent information such as the operating time and the type of oil and compressor in the system.

The data obtained after conversion showed that $75 \%$ of the lubricants tested contained less than $5 \%$ residual mineral oil (compared to a target of $<2-5 \%$ ), $130 \mathrm{ppm}$ moisture $(<50-100 \mathrm{ppm}$ ), $8 \mathrm{ppm}$ copper $(<10 \mathrm{ppm}), 10 \mathrm{ppm}$ iron $(<25 \mathrm{ppm}), 0.8 \mathrm{ppm}$ aluminum and had a TAN value $<0.07 \mathrm{mg} \mathrm{KOH} / \mathrm{g}$. These results compared favorably with the targets (shown in brackets above), which are considered to be suitable for long term stability by Swedish refrigeration companies. No target was given for the total acid number or for the dissolved aluminum content.

At low concentrations $(<50 \mathrm{ppm})$, the moisture data distribution did not follow the expected exponential drop off likely as a result of the differences in the analytical methods used by the 
different laboratories. Similarly, the distribution of the TAN results was found to be irregular at low concentrations. The lowest detectable TAN was reported to be $0.01 \mathrm{mg} \mathrm{KOH} / \mathrm{g}$.

The dissolved metal analyses included eighteen different elements. The most significant metals and their sources were given as:

\author{
$\underline{\text { Metal }}$ \\ aluminum, iron and copper \\ tin, lead \\ copper, tin, nickel and aluminum \\ silicon
}

\author{
$\underline{\text { Source }}$ \\ compressor wear \\ solder, valves and valve seats \\ brass and bronze valves and fittings \\ spent filter drier
}

Examination of the data showed that high acid levels (some greater than $0.2 \mathrm{mg} \mathrm{KOH} / \mathrm{g}$ ) were found to be associated with high concentrations of moisture and "catalyst" - defined as the mean value of copper, iron and aluminum content. Similarly, low "catalyst" levels were associated with low concentrations of moisture and acid. Some oil samples contained high moisture and acid concentrations but low "catalyst" values. These results were attributed to samples which were obtained shortly after the retrofit operation. In this scenario, hydrolysis of the lubricant ester had just started and the acid had not yet seriously attacked the copper. Other samples exhibiting high "catalyst" and acid concentrations but low water levels were attributed to samples which were obtained long after the conversion had taken place. The water content would then have been depleted through hydrolytic reaction with the lubricant to form acid which in turn reacted with copper to produce an elevated dissolved metal concentration.

The study also included a survey of refrigeration and heat pump consultants, installation and service companies responsible for 20,000 plants converted from CFC to HFC refrigerants. The survey results indicated that problems due to acid formation and copper plating could be avoided provided the residual mineral oil level was $<1 \%$ and the moisture content was $<50 \mathrm{ppm}$. Problems due to copper plating were thought to be exaggerated.

Preliminary results from sealed tube aging experiments indicated the chemical stability of the retrofitted system is unaffected by moderate increases in residual oil $(<2 \%)$ provided the moisture content is maintained below $50 \mathrm{ppm}$.

\subsection{SIGNIFICANT TAN VALUES}

Wojtkowski (1964) carried out a definitive study on 678 samples from normally operating and burned out R-22 systems to determine the critical TAN value for the mineral oil lubricants. Initially, the acidities of the refrigerants were also measured but since the values were generally found to be much lower than that of the lubricants except in extreme cases, only the lubricants were tested. Based on the results of 491 "normal" systems versus 187 "burned out" systems, the probability of finding an oil with a given TAN value was plotted for each data set (Figure 9) 


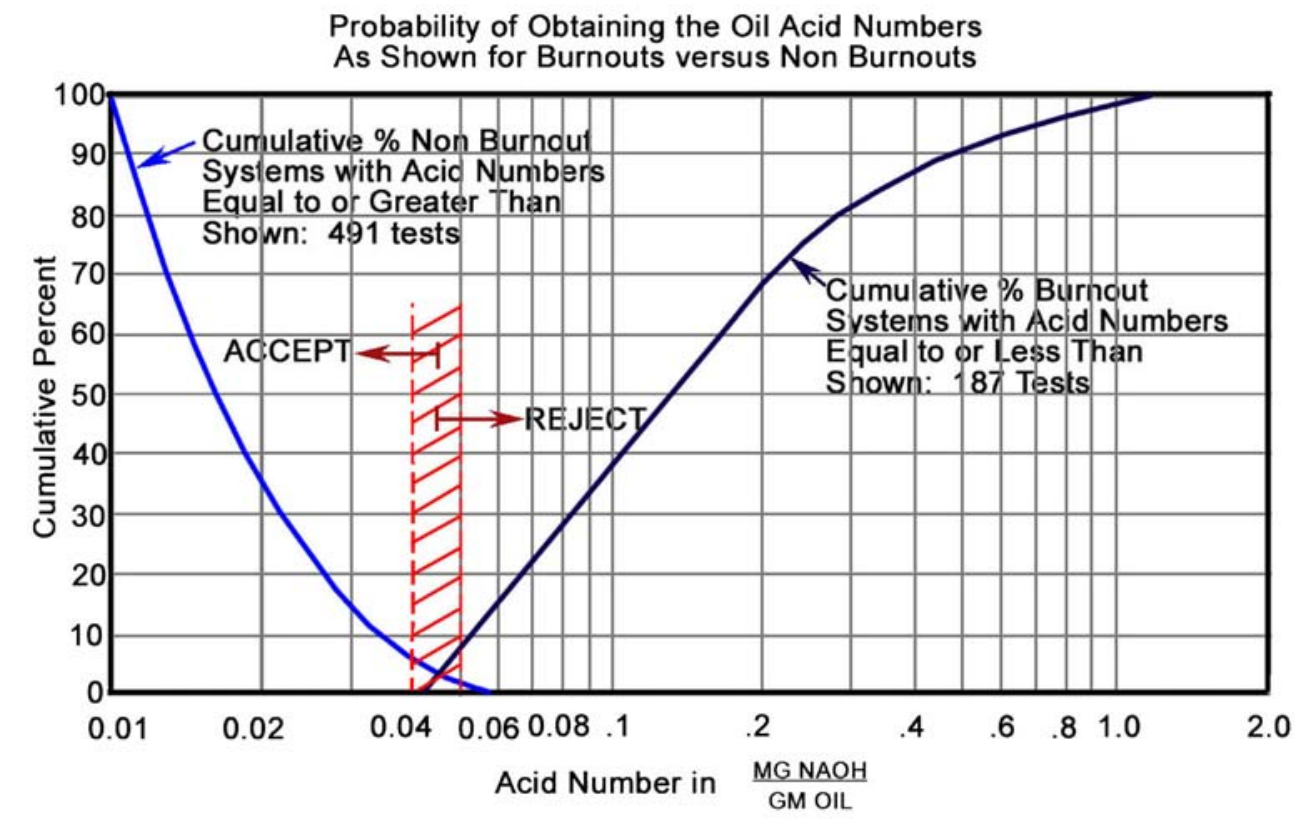

Figure 9. Lubricant Acid Number Distribution Probabilities in Normal vs Burnout R-22 Systems

(Wojtkowski 1964)

The two curves intersect at a probability of $3 \%$ and a TAN value of $0.05 \mathrm{mg} \mathrm{NaOH} / \mathrm{g}$ (rounded off from 0.045 ) which is the accepted refrigeration industry standard for mineral oil lubricants. Remedial action should be taken for oils having TAN values greater than 0.05 to avoid serious detrimental effects on the system.

Gibb et al (1999), reviewed critical parameters for effective and reliable refrigeration system operations using POE lubricants. They recommended the following critical TAN limits for POE:
- $<0.1$
- suitable for continued use
- $>0.1<0.2$
- suitable for use but testing frequency should be increased
- $>0.2$
- oil change should be considered

Henderson (2000) recently suggested that a TAN value of $1.5 \mathrm{mg} \mathrm{KOH} / \mathrm{g}$, after ASHRAE sealed tube aging for 14 days at $175^{\circ} \mathrm{C}$, should be regarded as an alarm level for POE degradation. The suggested value is reported to be based on hundreds of laboratory tests performed on many different POEs in sealed tubes with R-134a and common construction materials. This value is considerably higher than the TAN value of $0.5 \mathrm{mg} \mathrm{KOH} / \mathrm{g}$ after ASHRAE aging, which is generally regarded as a level of concern for mineral oil lubricants, because of the different types and strengths of the acids formed in the two types of systems. One would expect the critical TAN value for POE systems to be higher since the carboxylic acids formed in the POE systems are much weaker than the inorganic acids formed by degradation of mineral oil lubricants and are less aggressive towards metals. 
However, in either situation, once a critical point is reached, immediate remedial treatment should be performed to prevent serious damage to the system. The remedial treatment would involve either the removal of the acids by flushing or inactivation through neutralization. The suggested level appears to be a good starting point for POE assessment but does require a delay of 14 days for the accelerated testing. Ideally, the critical acid level, or an alternate indicator, should be determinable in a much shorter time frame, preferably within a day or two.

To supplement the limited information obtained in the literature review on suggested TAN limits for POEs, several refrigeration supply/consultation companies were also contacted.

Lilje (2003) indicated that CPI Engineering use $0.05 \mathrm{mg} \mathrm{KOH} / \mathrm{g}$ as a general maximum allowable TAN value for in-service POE but cautions that the value could be higher or lower depending upon the specific lubricant formulation (see discussion below).

Payne (2003) of Intertek provided manufacturers service bulletins which addressed maximum TAN values for polyolester lubricants. One manufacturer specified a maximum TAN value of $0.5 \mathrm{mg} \mathrm{KOH} / \mathrm{g}$ for POE compressor oils containing no lubricity enhancing additives. Another manufacturer suggested the following POE TAN rating scale:

- $\quad<0.1 \quad$ - system is okay

- $\quad>0.1<0.2 \quad-$ resample within 3 months to verify system stability, i.e., to ensure that oil breakdown is not occurring and that there is no moisture leak present - $\quad>0.2 \quad$ - replace the oil and the filter drier

Yost (2003) of National Refrigerants recommended the following general TAN classifications:

- $\quad<0.2 \quad-$ not a concern unless it is changing rapidly

- $\quad>0.2<0.3 \quad$ - system should be monitored closely

- $>0.3 \quad$ - immediate corrective actions should be taken

Due to their chemical origin, the acidic behavior of POEs in service conditions can be much more complex than that of mineral oils and the complexity can be further increased with the inclusion of acidic additives into the formulations. Yost (2003) suggested that POEs should be categorized into three general classes each having different acidity characteristics:

Class 1 Well manufactured POEs containing no acidic anti-wear/extreme pressure additives and having an initial TAN between 0.01 and $0.02 \mathrm{mg} \mathrm{KOH} / \mathrm{g}$. The low acid value would minimize potential autocatalytic effects of residual acid on the ester groups therefore tending to make these POEs more stable in the presence of moisture. 
Class 2 Poorly manufactured POE (possibly containing unreacted chemicals) containing no acidic additives and having initial TAN values of $0.05 \mathrm{mg} \mathrm{KOH} / \mathrm{g}$. These lubricants are likely to be less stable and acid buildup would be more rapid.

Class 3 POE lubricants formulated with acidic anti-wear/extreme pressure additives and having an initial TAN value near $0.2 \mathrm{mg} \mathrm{KOH} / \mathrm{g}$. The TAN values drop quickly in use to $<0.1$ as the acidic additives become absorbed on metal oxide surfaces within the system and on alkaline desiccant surfaces. Subsequent increases in the lubricant TAN values reflect changes within the system.

There are also special cases in which the acidic behavior of the lubricant system is more severely impacted by the selection of additives or lubricants. Additives such as "acid catchers" are sometimes used to improve the hydrolytic stability of POE lubricants. These are generally epoxides which can react with acid or moisture in order to protect the ester groups and thereby can significantly alter the acidity in the system until the additives are depleted. Other additives such as amine-based antioxidants may also act as neutralizers and delay acid buildup within the system. Similarly, specially formulated lubricants can have initial TAN values of up to $1.0 \mathrm{mg}$ $\mathrm{KOH} / \mathrm{g}$ which can significantly alter the expected acidity characteristics of the system.

Overall, there does not seem to be any industry consensus as to the critical TAN value for POE lubricants (ASHRAE 2002 Handbook on Refrigeration). The organic acids produced from POE degradation are much weaker and less corrosive to metals than the mineral acids produced from CFC degradation and found in mineral oil lubricants. The critical TAN value for POE should therefore be much higher than the $0.05 \mathrm{mg} \mathrm{KOH} / \mathrm{g}$ limit established for mineral oil systems. However, in order to establish the limit, a comprehensive study similar to that performed by Wojtkowski (1964) for CFC/mineral oils should be carried out for POE systems.

\subsection{ANALYTICAL METHODS}

\subsection{Titrimetric Total Acid Number}

\subsubsection{Lubricant}

Titrimetric Analysis - ASTM D 664

The standard method used for the determination of TAN and strong acid number of a lubricant oil is ASTM D-664, "Standard Test Method for Acid Number of Petroleum Products by Potentiometric Titration". Total acid includes strong acids such as $\mathrm{HCl}$ as well as weak organic acids such as pentanoic acid $\left(\mathrm{C}_{5} \mathrm{H}_{10} \mathrm{O}_{2}\right)$.

A reagent blank analysis for the TAN determination is carried out by titrating $125 \mathrm{ml}$ of toluene/isopropanol titration solvent with $0.1 \mathrm{M}$ alcoholic $\mathrm{KOH}$ solution to an end point of $\mathrm{pH}$ 11. A blank titration is also performed for the strong acid number by titrating the solvent blank with $0.1 \mathrm{M}$ alcoholic $\mathrm{HCl}$ solution to a $\mathrm{pH} 7$ end point. A weighed sample of the oil to be tested (sample size is variable depending on the acid levels but would be typically 5 to $10 \mathrm{~g}$ of used lubricant) is dissolved into $125 \mathrm{ml}$ of titration solvent and the 
mixture is then titrated with $0.1 \mathrm{M}$ alcoholic $\mathrm{KOH}$ titrant solution to the desired end point. ${ }^{*}$ The total acid number is determined by subtracting the blank titration value to $\mathrm{pH}$ 11 from the total amount of titrant required to attain an end $\mathrm{pH}$ of 11 with the sample mixture. The strong acid content is determined by summing the amount of titrant required to achieve an end $\mathrm{pH}$ of 7 for the sample mixture plus the amount of acidic titrant required to achieve a $\mathrm{pH}$ of 7 for the blank. The TAN value and strong acid number are calculated as follows:

Total Acid Number, $\mathrm{mg} \mathrm{KOH} / \mathrm{g}=(\mathrm{A}-\mathrm{B}) \mathrm{x} \mathrm{M}$ x 56.1/W ...................... Equ. 4

Strong Acid Number, $\mathrm{mg} \mathrm{KOH} / \mathrm{g}=(\mathrm{CM}+\mathrm{Dm})$ x 56.1/W ....................Equ. 5

where:

$\mathrm{A}=$ amount of alcoholic $\mathrm{KOH}$ solution used to titrate the sample to $\mathrm{pH} 11, \mathrm{ml}$

$\mathrm{B}=$ amount of alcoholic $\mathrm{KOH}$ solution used to titrate the reagent blank to $\mathrm{pH} 11, \mathrm{ml}$

$\mathrm{M}=$ concentration of alcoholic $\mathrm{KOH}, \mathrm{mol} / \mathrm{L}$

$\mathrm{m}=$ concentration of alcoholic $\mathrm{HCl}, \mathrm{mol} / \mathrm{L}$

$\mathrm{W}=$ sample weight, $\mathrm{g}$

$\mathrm{C}=$ amount of alcoholic $\mathrm{KOH}$ used to titrated the sample to $\mathrm{pH} 7, \mathrm{ml}$

$\mathrm{D}=$ amount of alcoholic $\mathrm{HCl}$ used to titrate the reagent blank to $\mathrm{pH} 7, \mathrm{ml}$

The titrations can be performed manually by recording the titrant volumes to the selected $\mathrm{pH}$ values but for large numbers of samples, an automatic titration instrument is generally used. Instead of using a potentiometer to determine the end points, $\mathrm{pH}$ color indicator solutions can be used to visually determine the end points. Methyl orange, which changes from pink/red to brown as $\mathrm{pH} 7$ is approached, and naphtholbenzien, which changes from orange to green or green-brown as $\mathrm{pH} 11$ is approached, are the $\mathrm{pH}$ indicators used (ASTM D-974). However, with dark or degraded oils, the color change at the end point of the titration can be obscured and the potentiometric method is recommended.

\subsubsection{Refrigerant}

\section{ARI Standard 700}

The standard method for determining acidity in new and used refrigerants is ARI Standard 700 Appendix C, Part 1, "Determination of Acidity in New and Reclaimed Refrigerants by Titration". The method, which is applicable for low, medium and high pressure fluorocarbon refrigerants, uses colorimetric titration to determine the acidity.

\footnotetext{
* The procedure can be scaled down to accommodate smaller oil samples such as those generated in ANSI/ASHRAE 97-189 accelerated aging tests. One-gram samples of the aged oil are added to $5 \mathrm{ml}$ of titration solvent and the titration is performed using $0.01 \mathrm{M} \mathrm{KOH}$.
} 
A few drops of Bromothymol blue indicator solution is added to toluene/isopropanol extraction solvent and the $\mathrm{pH}$ is adjusted to obtain a green coloration $(\mathrm{pH}=7.6)$ by drop wise addition of $0.01 \mathrm{~N}$ alcoholic $\mathrm{KOH}$ solution. The liquid refrigerant sample (50 to $100 \mathrm{~g}$ ) is added to or bubbled through $100 \mathrm{ml}$ of the $\mathrm{pH}$-adjusted solution which changes color to yellow if acid is present. The solution is then titrated with $0.01 \mathrm{~N}$ alcoholic $\mathrm{KOH}$ until the green end point is reached. The total acidity is given by:

Total Acidity, ppm as $\mathrm{HCl}=\mathrm{V} \times \mathrm{N} \times 36,500 / \mathrm{W}$ Equ. 6

where:

$\mathrm{V}=$ amount of alcoholic $\mathrm{KOH}$ solution used to titrate the solution, $\mathrm{ml}$

$\mathrm{N}=$ normality of alcoholic $\mathrm{KOH}$

$\mathrm{W}=$ weight of refrigerant sampled, $\mathrm{g}$

\subsection{Alternate TAN Methods}

\subsubsection{Ion Chromatography (IC)}

Unlike the titration methods above, which can be used to determine the total acid content or the amount of strong versus weak acid, ion chromatography can also be used to determine the amount of each individual acid present in an aqueous extract of the oil or refrigerant. A small quantity of the extract is injected into a pressurized stream of aqueous sodium hydroxide eluant solution. The solution flows into a column containing cation exchange resin, which interacts with each acid anion (negatively charged ion such as the fluoride ion, $\mathrm{F}^{-}$, from $\mathrm{HF}$ ) to a different degree, and thereby separates the mixture into individual acidic components. The individual anions pass through the column with different retention times (small anions such as $\mathrm{F}^{-}$have short retention times and pass through the column quickly whereas the larger anions such as hexanoate have much longer retention times) and are then detected using a conductivity detector (Field 1995). The acids are identified by their characteristic retention times and are quantitated by comparing the peak area or peak height obtained for each acid with values obtained with standard acids.

The sensitivity of the method ranges from 0.1 parts per million (ppm) for smaller anions such as fluoride, chloride and small organic ions such as acetate and formate, which produce sharp, easily-quantitated peaks, to $10 \mathrm{ppm}$ for larger anions (e.g., hexanoate, heptanoate) which produce broader peaks. Problems can be encountered with interferences due to unresolved or overlapping peaks but these can be resolved by judicious selection of eluant concentration. One limitation of the IC method, as it is usually employed, is the ability to quantitatively determine higher molecular weight organic acids (beyond hexanoic acid) because of the long retention times and broad peaks. To determine higher molecular weight organic acids, which may play a significant role in the lubricant degradation, a different ion exchange resin or an alternate technique such as gas chromatography of the derivatized acids would be required. 
Rohatgi et al (2001) compared the TAN values of refrigerants derived via titration, using ARI Standard 700-95, with values obtained by ion chromatography (IC). The individual acid concentrations found by IC were converted to equivalent $\mathrm{ppm}$ of $\mathrm{HCl}$ and the sum of the values was plotted against the ARI titration results but no correlation was found. The problem was attributed to an inability to detect higher molecular weight organic acids with the ion chromatography system used and to the colorimetric endpoint of the titration which gives a high value for the strong acid content but does not detect the end point for weak acids. Use of a different IC system or the use of GC-MS would improve the chromatographic results whereas more accurate titrimetric values could be obtained by plotting the titration curve, using the two end point indicators as per ASTM D 974 or by using potentiometric detection.

\subsubsection{Acid Test Kits - Semi-Quantitative Analysis}

The test kits provide semi-quantitive assessment of the oil/refrigerant acidity and therefore cannot be used for "tracking" or monitoring a system over time. However, since the kits provide a convenient, immediate assessment of the acidity on-site, they are widely used throughout the refrigeration industry for testing field units. The kits essentially provide a pass/fail test although some kits also have an intermediate acid level stage. There are a number of different kits available on the market for testing lubricants and/or refrigerants. Most of the kits are based on the color change of a $\mathrm{pH}$ indicator test strip or reagent when exposed to the sample. One test kit is based on a change in dielectric strength and employs a short ion exchange column to separate conductive materials which are detected colorimetrically. Some manufacturers kits are specific for either mineral oil or POE but some kits claim to be able to assess both types of lubricants by varying the quantity of fluid tested. Critical TAN levels for mineral oils have been established $(0.05 \mathrm{mg} \mathrm{KOH} / \mathrm{g})$ however critical levels for POE do not appear to have been established.

\subsection{ALTERNATIVE TEST TECHNOLOGIES}

Lubricants now in use or under consideration as new environmentally friendly refrigerants are mineral oils, alkylbenzenes, POEs, PAGs, modified PAGs, and PVEs. Although POEs are the primary subject of this report, the other possible candidates might appear as cross-contaminants in reconditioned refrigeration systems. Polyol esters, aside from the chemical type of alcohol and acid used for their manufacture, deserve special considerations. Their response to stress as encountered in refrigeration systems, regardless whether these are parameters of mechanical, electrical, chemical stress, or a combination thereof, may be quite different from those of hydrocarbon - based lubricants. 
Three alternative methods of lubricant analysis, other than viscosity and TAN, were selected as possible candidates and shall be discussed:

1. Free Radicals

2. Voltammetry

3. FTIR Spectroscopy

The authors of "Opportunities for On-Line Machinery Sensing" (Murray and Ling 1996) provide a list of six items, which are recognized indicators for the deterioration of lubricants. Number one in their list is the "production of free radicals, which form hydro-peroxides and peroxides as a result of initial oxidation reactions between the hot (stressed) oil and the ambient air".

Free radicals are the first entities to form as a result of stress and the ageing of lubricants. This is the reason why Powertech Labs chose the detection of free radicals, voltammetry, and/or FTIR spectroscopy as possible alternative techniques for the monitoring of lubricant quality. Free radicals or hydro-peroxides may be measured directly or indirectly. The indirect technique consists of monitoring the levels of oxidation inhibitor, which are frequently used to control free radicals. If these methods fail, the final oxidation products may be monitored by FTIR spectroscopy.

There are several reasons for suggesting these alternative methods as they might provide earlier and better indications for problems with the lubricant chemistry and thus have the potential to replace TAN.

\subsection{Free Radicals}

The mechanism of auto-oxidation of hydrocarbon lubricating oils is a well-researched and established subject (Hamblin et al 1989, Mayo 1968). It is generally accepted that it follows the mechanism for low molecular weight saturated hydrocarbons in the liquid phase, i.e., it is a free radical chain mechanism consisting of the following steps:

\section{Initiation \\ Chain Propagation \\ Chain Branching \\ Chain Termination}

Stresses of heat, light, electrical or mechanical nature initiate a chain of events, which may be aided by the presence of catalysts. The outcome is a self-supporting, progressive oxidation (autooxidation) of the lubricating oil. It is assumed that this mechanism of auto-oxidation also applies 
to the oxidative degradation of POE-based lubricating oils, at least during the initial phase of oxidation (Duncan et al 2002, Bakunin and Parenago 1992, Jensen et al 1984). Many aspects of POE oxidation remain unclear and it appears that two approaches to the oxidation mechanism of POE lubricants exist; one mechanism emphasizes the import of alcoholic fragments, while the other approach provides experimental evidence for the import of acyl fragments. Bakunin and Parenago (1992) suggest that the actual process includes both mechanisms and all polyol fragments participate in the oxidative degradation, the details of which are dictated by chemical structure and environmental conditions.

The mechanisms of initiation and chain propagation (Hamblin et al 1989) for the auto-oxidation of lubricating oils are assumed to be very similar, for both hydrocarbon-based and polyol esterbased lubricating oils:

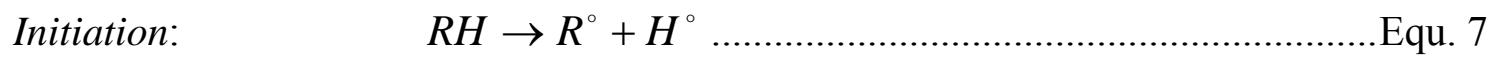

Chain Propagation: $\quad \mathrm{R}^{\circ}+\mathrm{O}_{2} \rightarrow \mathrm{ROO}^{\circ}$.......................................................... Equ. 8

$$
R O O^{\circ}+R H \rightarrow R^{\circ}+R O O H
$$

As was mentioned before reaction (7) is stress induced, aided by catalysts and gets the chain reaction started, while (8) is the oxygen absorbing step, which results in the formation and accumulation of the hydro peroxides ROOH (9) and perhaps their accumulation. Reaction (8) is faster than reaction (7). The acceleration of the process, which initially got its start with a stress induced hydrogen loss (7) of a lubricant moiety "RH", will take place with the splitting of $\mathrm{ROOH}(9)$ and accompanying chain branching:

$$
\begin{aligned}
& \text { Chain Branching } \quad \mathrm{ROOH} \rightarrow \mathrm{RO}^{\circ}+{ }^{\circ} \mathrm{OH} \text {................................................. } 10
\end{aligned}
$$

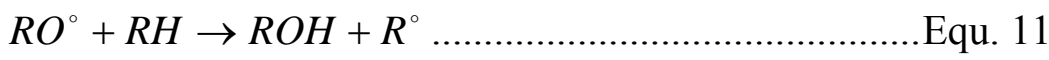

$$
\begin{aligned}
& { }^{\circ} \mathrm{OH}+\mathrm{RH} \rightarrow \mathrm{H}_{2} \mathrm{O}+\mathrm{R}^{\circ} \text {.........................................Equ. } 12
\end{aligned}
$$

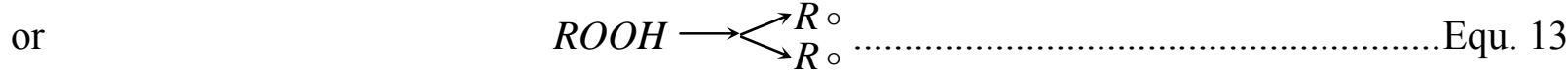

Primary antioxidants are used to inhibit equations (8) and (9) by reacting with the alkyl and peroxy radicals and thus eliminating oxygen uptake. The result is an oxidation induction period " $\tau$ ", after which oxygen uptake re-commences. Secondary antioxidants are practically void of an "induction period" and react with oxygen or hydro-peroxides directly. This results in a 
contribution of additional degradation products. Once these additives are consumed, autooxidation of the lubricant resumes. Antioxidants are essential. Lubricants like POEs are susceptible to absorb water and oxygen during storage resulting in the formation of hydroperoxy oxidation products (Cavestri 1996). Secondary antioxidants act as a kind of reserve additive once the primary antioxidants are gone, or they may act in synergy with the same. Protective surface films and metal deactivators will inhibit the catalytic action of copper and iron.

Chain branching occurs if the energy input is high enough to provide the necessary energy of activation " $\mathrm{E}_{\text {act"}}$ ", which is, in the case of (10) and (13), about $32 \mathrm{kcal}$. This energy requirement will be met at a lubricating oil temperature of about $150^{\circ} \mathrm{C}$. Substantially lower temperatures suffice in the presence of an effective catalyst such as ions of copper or iron. (Localized hotspots $\geq 150^{\circ} \mathrm{C}$ too will promote the reaction (10)).

In the case of the auto-oxidation for polyol ester oils there is a question as to the exact identity at any given time of " $\mathrm{R}$ " in the entities $\mathrm{ROOH}, \mathrm{ROO}^{\circ}, \mathrm{RO}^{\circ}$ and $\mathrm{R}^{\circ}$.

Questions of this nature are of theoretical interest only and, for our purposes of the laboratory and field-testing of refrigeration oils, are of lesser importance. The emphasis is on the determination of the total free radical concentration and its relationship to the remaining useful life or "RUL" of the refrigeration oil.

Work performed at Powertech Labs Inc. in the related field of transformer oils has shown that a maximum of free radical scavenging activity precedes an increase of TAN and the formation of sludge during the oxidation of conventional insulating oil (ASTM D2112). The knowledge of the concentration might be used empirically to determine the magnitude of stress or the progress of deterioration encountered by a given hydrocarbon oil. The validity of such an approach is shown by the experimental findings as shown in the Figure 10, where the "oxidation time" (ASTM D2112) is graphed against "relative free radical activity". The peak of free radical scavenging activity occurs, as can be seen, before the onset of "acid number" and "sludge formation" (particles greater than $5 \mu \mathrm{m}$ and $10 \mu \mathrm{m}$ ). Powertech Labs Inc. used 2,2-Diphenyl-1picrylhydrazyl reagent (DPPH) to follow the free radical scavenging activity in the hydrocarbon oil. 


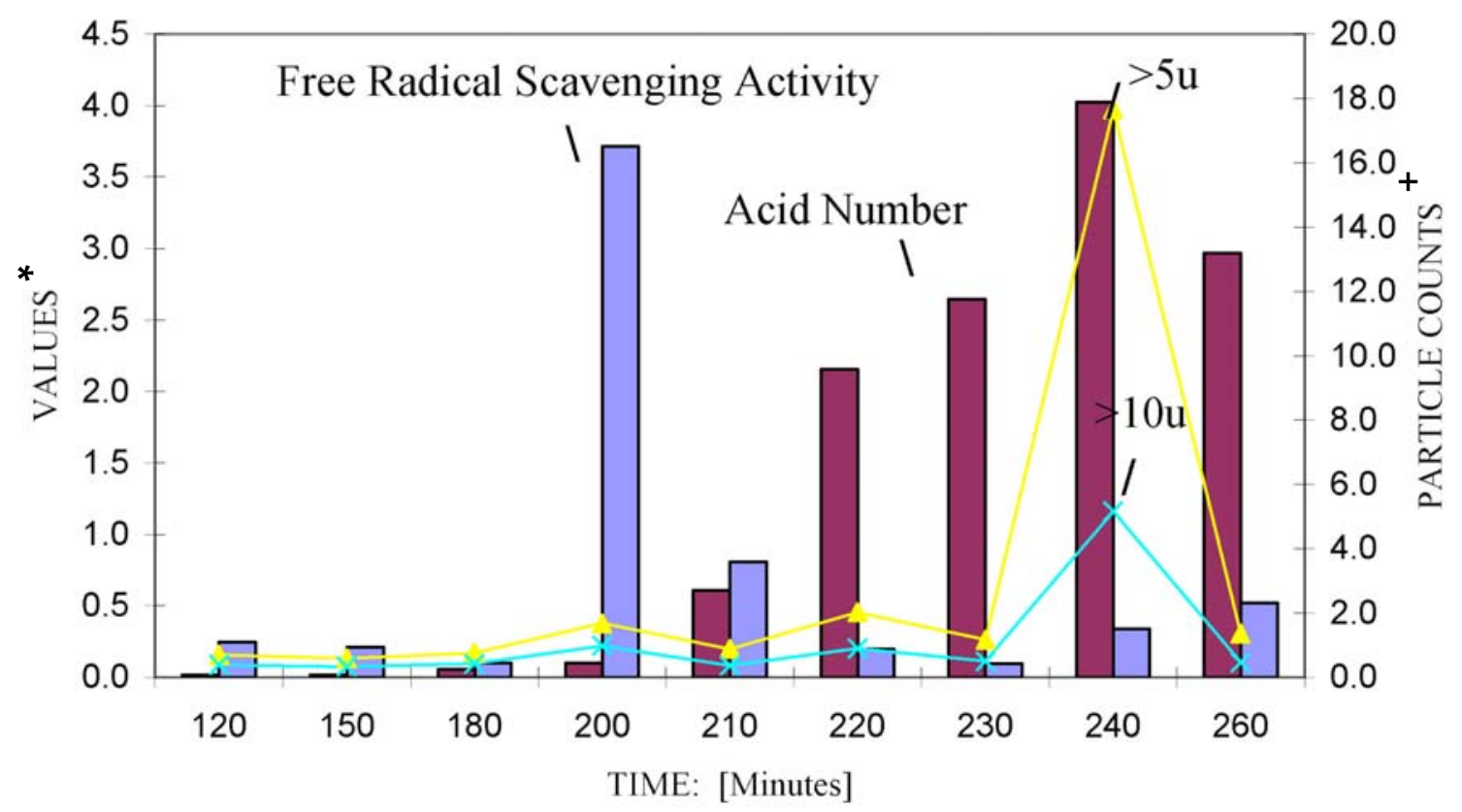

Figure 10. Oxidation Time vs Free Radicals, TAN and Particulates

(Powertech Data)

$\begin{aligned} * \text { VALUES: } & =(\mathrm{mg} \mathrm{KOH} / \mathrm{g} \text { Oil }) \text { in the case of Acid Number } \\ & =(1 / \text { second }) \text { in the case of Free Radical Scavenging Activity } \\ { }^{+} \text {PARTICLE COUNTS: } & =\text { Number of Particles }(>5 \mu,>10 \mu)\end{aligned}$

Findings by researchers using different techniques confirm the validity of this approach (Mayo 1968, Mahoney 1969, Willermet et al 1978, Mahoney et al 1978, Korcek et al 1980 and Hsu et al 1986).

Other researchers addressed equation (7) and measured the oxygen uptake directly (Willermet et al 1978, Mahoney 1978, Korcek et al 1980, Jensen et al 1984). The authors note in their NBS special publication, "Antioxidant Consumption and Oxidative Degradation of Lubricants" that in contrast to standard determinations of viscosity, acid number, and insolubles, the method provides information on lubricant oxidative degradation in the earliest periods of testing. These researchers determined the oxidation induction period " $\tau$ " after which oxygen uptake commences using azobisisobutyronitrile as a free radical initiator.

While all these papers deal with the determination and consumption of antioxidants, they also considered the useful lifetime of lubricant. Accordingly, it was suggested that the method may be useful in establishing correlations between laboratory tests and service use and in the development of predictive chemical models for the useful lifetimes of lubricants (Mahoney et al 1978).

In Continental Europe a similar objective is reached by the determination of the "Peroxide Value" using method "DGF C-IV 6a". Powertech Labs Inc. tried to determine the peroxide 
value of hydrocarbon based transformer oils by using ASTM D 3703, but these investigations resulted in inconclusive data and this approach was abandoned in favor of an in-house DPPH method.

\subsection{Voltammetry}

Voltammetry techniques include electro-analytical procedures that are based upon the potentialcurrent behavior of a small, easily polarized electrode immersed in the solution being analyzed (Skoog and West 1976). Amperometric titrations belong to this group of analytical techniques.

The oxidative degradation of hydrocarbons and polyol esters result in the formation of oxygenated compounds such as alcohols, aldehydes, ketones, carboxylic acids, carbon oxides and water among others. The formation of these compounds is preceded by the formation of free radicals, hydro-peroxides and peroxides. The degree of deterioration of lubricants is traditionally monitored using different techniques such as:

- Total Acid Number (TAN)

- Viscosity

- Fourier Transform Infrared Spectroscopy (FTIR)

- Rotating Bomb Oxidation (RBOT, ASTM D2112)

- High Pressure Differential Scanning Calorimetry (HPDSC)

- RULER and Voltammetry

The remaining useful life (RUL) for aircraft turbine lubricants is determined by cyclic voltammetry (CV). RULER ${ }^{\mathrm{TM}}$ is the trademark of an Oil Analysis Instrument (Ameye 2002). Cyclic voltammetry is similar to linear sweep voltammetry (LSV), but the voltage is swept between two values $V_{1}$ and $V_{2}$ at a fixed rate and the scan is reversed each time it reaches either of the two values. The variation of peak position as a function of scan rate is analyzed and allows estimates for electron transfer rate constants. RULER ${ }^{\mathrm{TM}}$ exploits these principles by monitoring redox reactions in the oil with a three-electrode system.

Figure 11 shows the remaining useful life (RUL) for a railroad diesel engine oil stressed at $150^{\circ} \mathrm{C}$ as a function of TAN, viscosity and remaining additive. The remaining useful life is the number of hours to reduce the concentration of remaining additive to zero percent. 


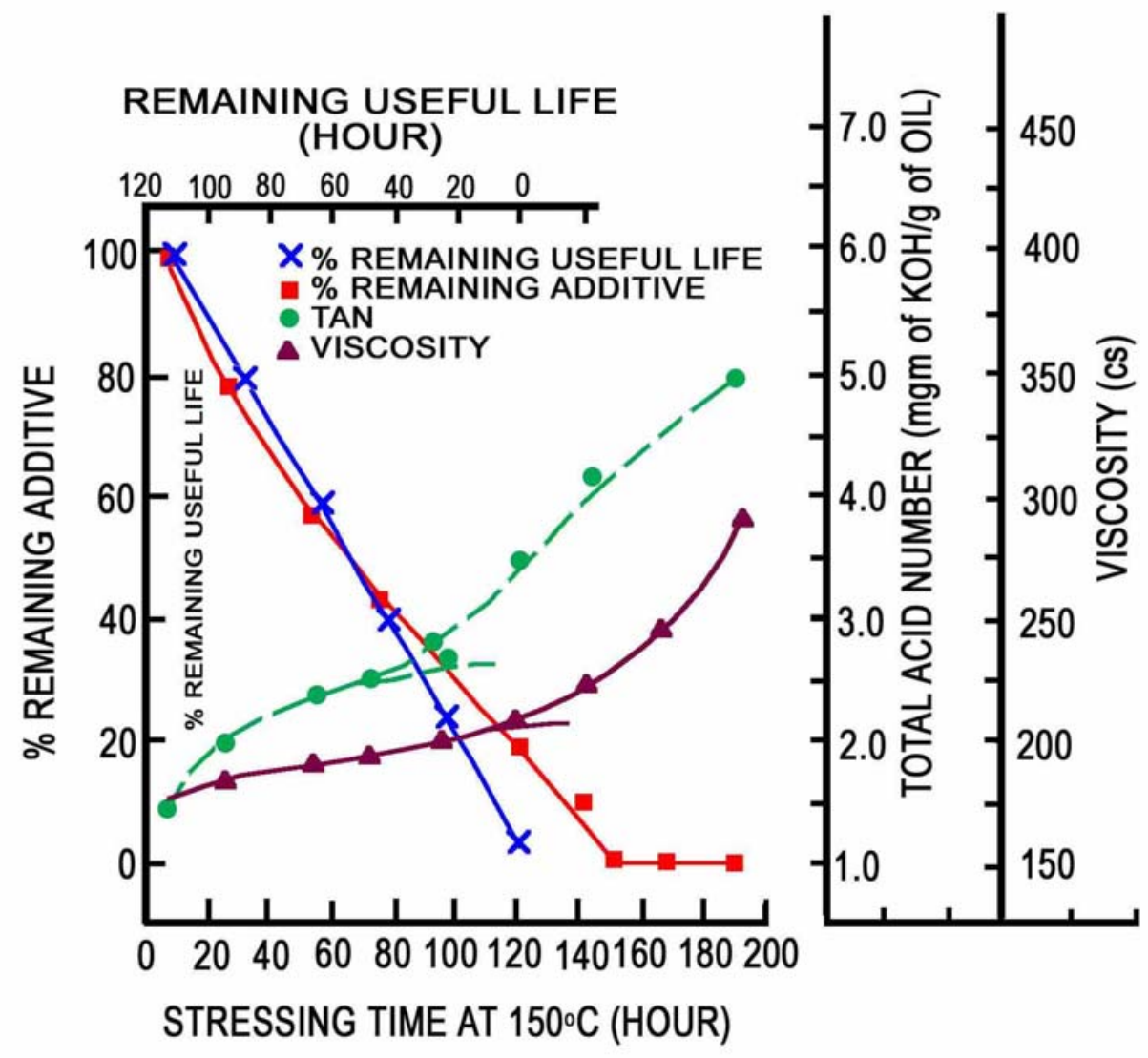

Figure 11: Factors Affecting Remaining Useful Life of Oil (http://www.fluitec.com/education2.html)

Ameye (2002) suggests that cyclic voltammetry can be used to determine RUL, the amount of time for oxidant depletion, for lubricants regardless of oil formulation or stressing conditions. The method may be applicable to POE lubricants used for refrigeration systems with the appropriate limiting values superimposed into the graph.

The trademark instrument "RULER ${ }^{\mathrm{TM}}$ " is a portable instrument with a three-electrode assembly, consisting of:

- A glassy carbon working electrode

- A platinum wire electrode

- A platinum wire auxiliary electrode 


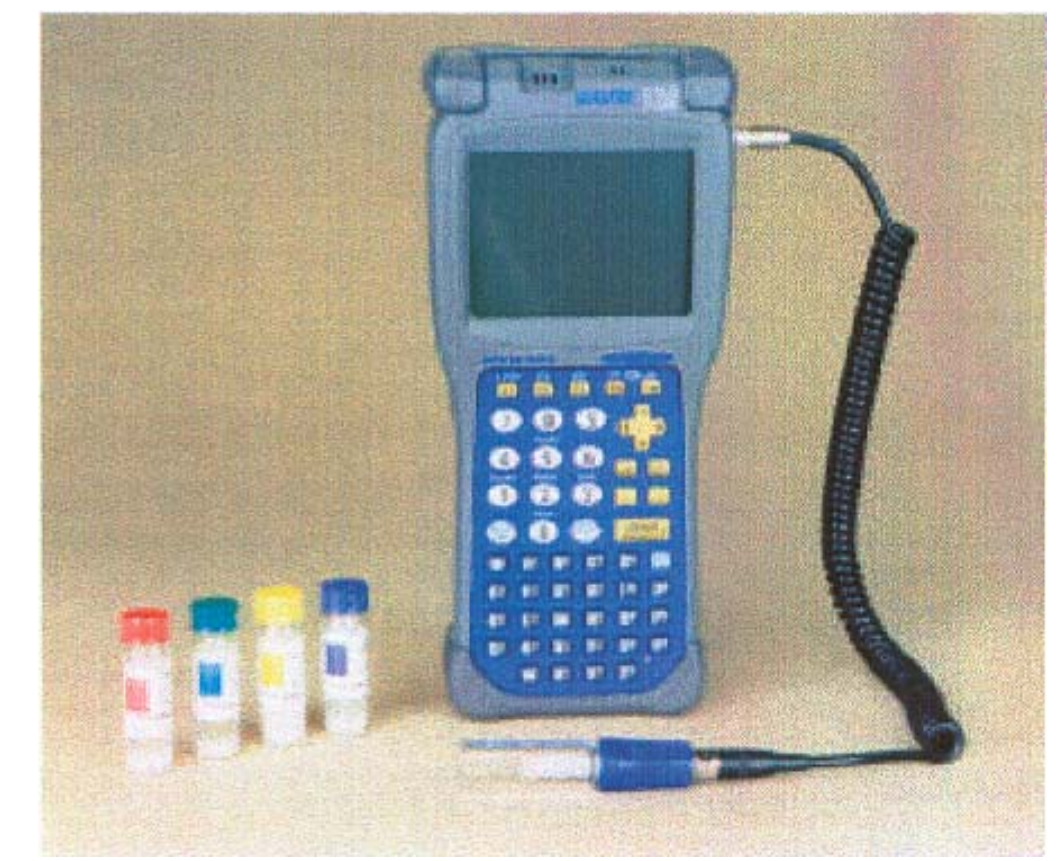

Figure 12: Portable RULER ${ }^{\circledR}$ Condition Monitoring Instrument

(Ameye 2000)

A small amount of the oil sample $(200-400 \mu \mathrm{l})$ is dissolved in $5 \mathrm{ml}$ of solvent in a small vial and the three-electrode assembly is inserted. The current is monitored as the voltage is increased until it reaches the oxidation potential of the antioxidant present in the oil to produce a peak due to the increased current flow. The portable RULER ${ }^{\mathrm{TM}}$ instrument scans from $0.0 \mathrm{~V}$ to $1.5 \mathrm{~V}$ at a rate of $0.2 \mathrm{~V} /$ seconds. An experienced operator can complete a test within five minutes.

Figure 13 shows a scan of the voltage increase with time " $\tau$ " versus current $(\mathrm{mA})$ for an oil containing three different antioxidants. 


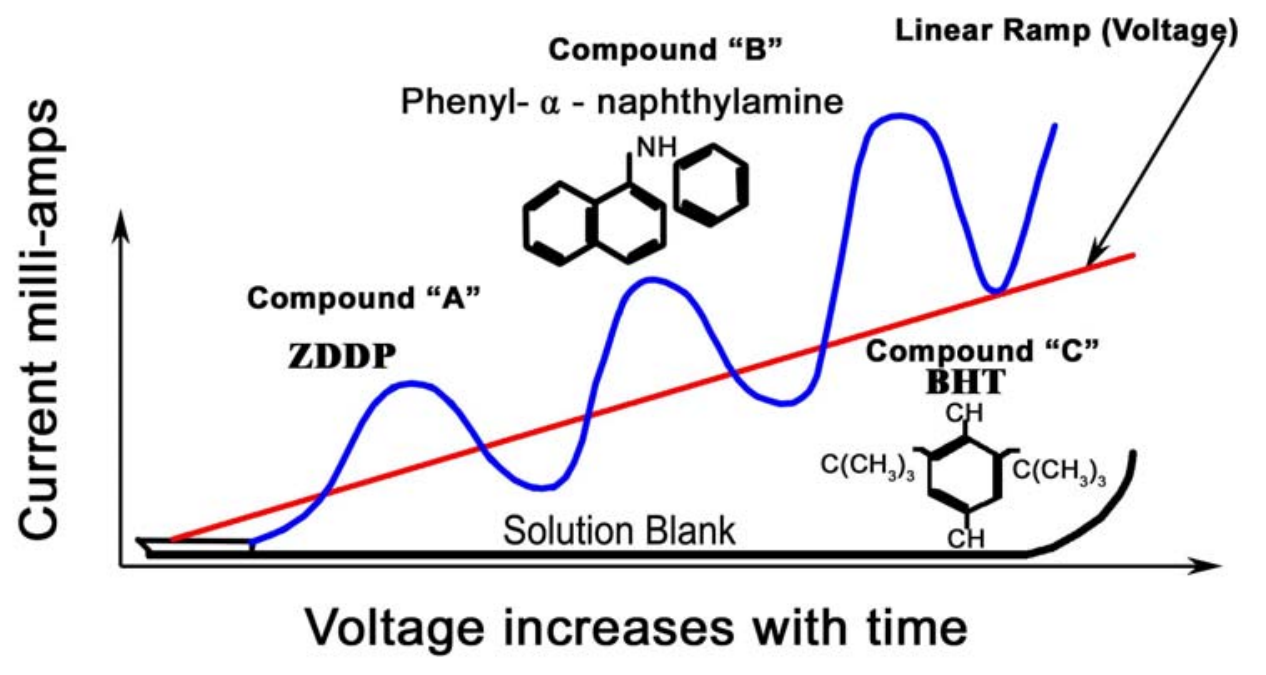

Figure 13 Determination of Antioxidants by Cyclic Voltammetry

(Ameye 2002)

Leeuen et al (1998) investigated the use of RULER ${ }^{\mathrm{TM}}$ for ester based hydraulic fluids and concluded that the method was applicable for the determination of the critical antioxidant concentrations in laboratory aged hydraulic fluids. They indicated that the remaining useful life of field samples can be estimated by comparing the antioxidant concentration(s) with the increase of acid number and viscosity at $40^{\circ} \mathrm{C}$ and that trend analysis of antioxidant concentrations will improve the lifetime estimations.

Jeffries et al (1998) documented the usefulness of RULER ${ }^{\mathrm{TM}}$ for testing engine lubricants. These investigators report precisions of $2.5 \%$ relative standard deviation (RSD) for additives, but state also that the instrument should not be used as a stand-alone technique but as a technique which can add useful information in conjunction with other analytical data.

Herguth and Phillips (1994) compared different lubricating oils before, during and after stressing by the Turbine Oxidation Stability Test (TOST), ASTM D943. The samples were evaluated for the remaining levels of antioxidants by common methods of lubricant analysis and compared with voltammetric data from a commercially available instrument $\left(\operatorname{RULER}^{\mathrm{TM}}\right)$. Figure 14 shows the correlation between the two methods. 


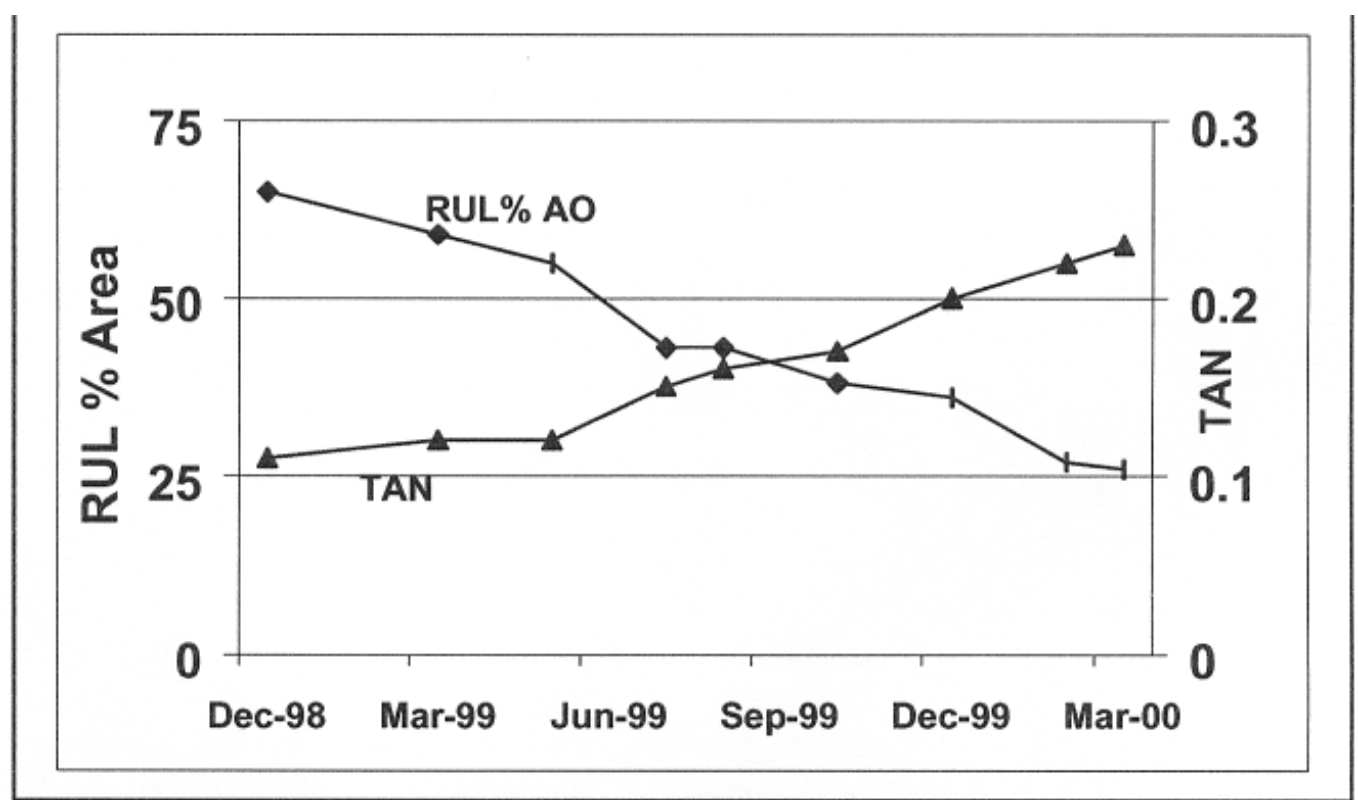

Figure 14. Correlation of RUL\% versus TAN

(Ameye 2000)

The final data are presented in form of a matrix of Oil Type and Linear Regression Correlation Coefficients, which compare the final results of Rotating Bomb Oxidation Stability (RBOT) and Differential Scanning Calorimetry (DSC) with those of Cyclic Voltammetry (RUL) for the same samples (Table 4)

A good correlation was found between traditional methods and Voltammetry except for the synthetic and hydraulic oils (chemical composition not identified).

TABLE 4

Correlation of RUL\% with RBOT and DSC Results

(Herguth et al 1994)

\begin{tabular}{|c|c|c|}
\hline OIL TYPE & RBOT & DSC \\
\hline High Performance Turbine Oil & 0.85 & 1.00 \\
\hline Circulating Oil & 0.95 & 0.87 \\
\hline Turbine Oil No. 4 & 0.84 & 0.95 \\
\hline Turbine Oil No. 5 & 0.92 & 0.96 \\
\hline Synthetic Hydrocarbon Oil & -0.15 & 0.77 \\
\hline Hydraulic Oil & 0.36 & 0.18 \\
\hline
\end{tabular}




\subsection{FTIR Spectroscopy}

Infrared Spectroscopy has been an analytical mainstay for lubricant investigation for many years. It has the ability to "fingerprint" materials, which is especially useful for the identification of lubricants. In addition infrared, especially its more recent form of Fourier Transform Infrared (FTIR) which is much faster and more sensitive than older dispersive infrared technique, can be used for quantitative evaluation of the organic acids.

Dong et al (2000) examined FTIR for the analysis of the carboxylic content of TAN in lubricating oils. Carboxylic acids absorb infrared radiation at $1710 \mathrm{~cm}^{-1}$, however other materials such as additives can also contribute to this peak. The oil sample was split into two portions; alcoholic $\mathrm{KOH}$ was added to one portion in order to convert the carboxylic acids present to carboxylate anions whereas hexanol was added to the other portion. Differential spectra were then obtained for the two samples at $1565 \mathrm{~cm}^{-1}$ which corresponds to the maximum for the carboxylate salts. The method is claimed to have reproducibility advantages over both the potentiometric ASTM D 664 procedure and colorimetric ASTM D663 and D974 for darkened oils; however, the sensitivity of the method may be insufficient for refrigeration lubricants.

FTIR may also be used for monitoring the degradation of POEs and halogenated refrigerants (Jeffrey and Ameye 1998). Examples of such regions include:

1. Broad peak that appears with thermal ageing at around $3528 \mathrm{~cm}^{-1}$ due to the presence of hydroxyl groups

2. Slight growth of a peak at around $1050 \mathrm{~cm}^{-1}$ due to the C-O stretching of primary alcohols

3. Strong peak at around $1200 \mathrm{~cm}^{-1}$ due to ester groups C-O-C stretching modes

4. A peak at around $1750 \mathrm{~cm}^{-1}$ due to the $\mathrm{C}=\mathrm{O}$ band

5. Water around $3260 \mathrm{~cm}^{-1}$

6. Nitrogenous materials around $1650 \mathrm{~cm}^{-1}$

7. Halogenated hydrocarbons around $1110 \mathrm{~cm}^{-1}, 910 \mathrm{~cm}^{-1}$, and $830 \mathrm{~cm}^{-1}$

8. Depletion of additive zinc-dialkyldithiophosphate (ZDDP) at $1000 \mathrm{~cm}^{-1}$

The most common function of additives is the protection against wear, ageing, oxidation and excessive deposit formation. Rather than measuring these properties directly, it is quite common to determine the additive concentration and, based on the depletion, decide whether the lubricant is in need of replacement.

Quantitative techniques depend on spectral interferences and the chemical composition of the refrigeration oil (polyol ester), the impurities of the new and aged polyol ester oil. Algorithms of good precision, which allow for spectral corrections, can become quite complex and good final results are sometimes impossible to achieve because of too many variables. 
In the case of highly optimized polyol ester (HOPOE), where the use of additives is required, the additive(s) level in the formulation is of great importance. Level(s) that are too low or too high can cause problems, and techniques to measure them are important. Aside from gas/liquid chromatography, RULER ${ }^{\mathrm{TM}}$ and other techniques, FTIR might be applied in the laboratory to provide a quick and decisive answer (Gibb et al 1999). The elucidation of interactions between additive and synthetic lubricant are a concern, often because there is a lack of documentation and experience with certain combinations and their interactions. Fourier Transform Infrared Spectroscopy is a powerful investigative tool in such circumstances (Donahue and Haggett 2002). The FTIR method is fast and efficient, but usually doesn't lend itself easily for fieldtesting due to lack of portability and high costs.

\subsection{Other Methods}

Methods other than the ones discussed here exist, for example the determination of the RUL by differential scanning calorimetry (DSC) and sealed capsule differential scanning calorimetry (SCDSC) (Bowman and Stachiowiak 1996). This method too relies indirectly on the formation of peroxides and free radicals.

Most of the alternate methods discussed have been developed for analysis of automotive lubricating oils, which tend to have high TAN values, and the methods may not have the sensitivity required for monitoring refrigeration lubricants.

\subsection{Conclusions}

1. Acid number, as determined by ASTM D 664 titrimetric analysis, is a useful indicator for condition assessment of refrigeration systems since acidity plays a major role in system degradation processes.

2. There is no consensus within the industry as to a critical TAN value for HFC/POE systems. The value will, however, be much higher than the $0.05 \mathrm{mg} \mathrm{KOH} / \mathrm{g}$ critical TAN value for $\mathrm{CFC} / \mathrm{mineral}$ oil systems due to the much weaker organic acids produced in $\mathrm{HFC} / \mathrm{POE}$ systems.

3. Ion chromatography is a useful technique for analysis of POE lubricant decomposition products since the amount of the individual organic acids produced can be determined. In addition, the concentration of ionic degradation products from the refrigerant can also be determined. The technique would be particularly useful for determination of the acid content of lubricants containing acidic additives.

4. Problems such as corrosion and copper plating commonly found due to degradation of the older $\mathrm{CFC} / \mathrm{HCFC} /$ mineral oil systems do not appear to be as prevalent with the $\mathrm{HFC} / \mathrm{POE}$ systems likely due to the much weaker organic acids generated by hydrolysis of the POE. 
5. The problem of capillary plugging appears to be enhanced with the new systems due to the formation of insoluble carboxylic salts from the reaction of the carboxylic acids from POE hydrolysis with the system metals, predominantly iron. Residual processing chemicals from the manufacturing operations appear to accelerate the blockage formation by providing a contaminant buildup on the capillary surfaces.

\subsection{Recommendations}

1. A study should be undertaken to establish the minimum levels at which acid values in refrigeration POE lubricants begin to have a detrimental effect on system and compressor performance and reliability. This would entail the collection and analysis of used lubricants from operating units in the field as well as systems which have failed in service. A database would then be established to include acid values as well as moisture contents and dissolved metals from the used lubricants. Pertinent operational data as well as service history should also be included in the database. The database could then be used to establish diagnostic tools to assess and maintain system conditions to minimize the possibilities of catastrophic failure.

2. Alternative condition monitoring techniques such as free radical determination and voltammetry should be investigated to determine whether the methods are applicable to refrigeration systems. If successful, these techniques may provide an earlier indication of refrigeration system deterioration than the currently used titrimetric acidity analysis. 


\section{BIBLIOGRAPHY:}

1. Ameye, J., "Rapid and Cost-effective Determination of the Remaining Useful Life (RUL) of Industrial Lubricants by Voltammetric Techniques", Pres. Oil Anal. Conf., Tulsa, Oklahoma, 24-26 ${ }^{\text {th }}$ October 2000.

2. Ameye, J., "The Results of a program for Quick Determination of Antioxidants on 0-160 Helicopter Turbine Lubricants by Using the RULER Oil Analysis Instrument, FLUITEC International, Brussels, Belgium, 2002. j.ameye@fluitec.com;

3. ARI Standard 700-95, Appendix C, "Determination of Acidity in New and Reclaimed Refrigerants by Titration", Air-Conditioning and Refrigeration Institute, Arlington, VA, 1995.

4. ASHRAE Standard 97-1983, "Sealed Glass Tube Method to Test the Chemical Stability of Material for Use Within Refrigeration Systems", American Society of Heating, Refrigeration and Air-Conditioning Engineers, Atlanta, GA, 1995.

5. ASHRAE Handbook CD, 2002 Refrigeration, American Society of Refrigerating and Air-Conditioning Engineers, Inc., Atlanta, GA, 2002.

6. ASTM D-664, "Standard Test Method for Acid Number of Petroleum Products by Potentiometric Titration", ASTM International, Westconshocken, PA, 1998.

7. ASTM D 943, "Standard Method for Oxidation Characteristics of Inhibited Mineral Oils", ASTM International, Westconshocken, PA, 2001.

8. ASTM D-974, "Standard Test Method for Acid and Base Number by Color-Indicator Titration", ASTM International, Westconshocken, PA, 1998.

9. ASTM D 3703, "Standard Test Method for Peroxide Number of Aviation Turbine Fuels", ASTM International, Westconshocken, PA, 1998.

10. Bakunin, V.N., and Parenago, O.P., "A Mechanism of Thermo-oxidative Degradation of Polyol Ester Lubricants”, J. Syn. Lubricants, 9, 2, pp 128-143, 1992.

11. Bartnikas, R., "Electrical Insulating Fluids", ASTM Monograph 2, Engineering Dielectrics Volume 3, 1994.

12. Bowman, W.F., Stachowiak, "New Criteria to Assess the Remaining Useful Life of Industrial Turbine Oils", J. Soc. Trib. Lubr. Eng., July 1996

13. Boyde, S., and Wilton, U., "Hydrolytic Stability of Synthetic Ester Lubricants", J. Syn. Lubr., 16, 4, pp 297-312, 1999. 
14. Cavestri, R.C., "Potentially Useful Polyolester Lubricant Additives. An Overview of Antioxidants, Antiwear, and Antiseize Compounds"; Proc. 1996, Intl. Ref. Conf.; West Lafayette, Indiana, July 23 - 26, 1996

15. Cavestri, R.C., and Schooley, D.L., "Compatibility of Manufacturing Process Fluids with R-134a and Polyolester Lubricant", ARTI MCLR Final Report DOE/CE/23810-55, AirConditioning and Refrigeration Technology Institute, Arlington, VA, 1996.

16. Cavestri, R.C., "Compatibility of Lubricant Additives with HFC Refrigerants and Synthetic Lubricants", ARTI MCLR Final Report DOE/CE/23810-76, Air-Conditioning and Refrigeration Technology Institute, Arlington, VA, 1997.

17. Cavestri, R.C., and Schooley, D.L., "Test Methods for Inorganic Acid Removal Capacity in Desiccants Used in Liquid Line Driers", ASHRAE Trans. Vol. 104, Pt 1B, pp 13351340, 1998.

18. Cavestri, R.C., Falconi, E., Ruona, K.S., and Schooley, "Effect of Selected Contaminants in Air Conditioning and Refrigeration Equipment", ARTI MCLR Final Report DOE/CE/23810-111, Air-Conditioning and Refrigeration Technology Institute, Arlington, VA, 2000.

19. DeVos, R., "R-134a Qualification - Industry Refrigeration Capillary Data", ASHRAE Transactions: Vol. 103, Pt 2, pp 640-648, 1997.

20. DGF C-IV 6a, "Peroxide Value", Deutche Gesellschaft fur Fettwissenschaft, German Institute of Lipid Sciences. http://www.dgfett.de/

21. Donahue, A., and Haggett, R., "Additive Interaction in Synthetic Lubricating Oil", Lubr.\& Fluid Power, November, 2002.

22. Dong, J., Van der Voort, F.R., and Ismail, A.A., "Rapid Determination of Carboxylic Acid Contribution to the Total Acid Number of Lubricants by Fourier Transform Infrared Spectroscopy", Lubr. Eng. 12-20, 2000.

23. Duncan, C., Reyes-Gavilan, J., Costantini, D. and Oshode, S., "Ashless Additives and New Polyol Ester Base Oils Formulated for Use in Biodegradable Hydraulic Fluid Applications", J. Soc. of Trib. and Lubr. Eng., Vol. 58, No. 9, September 2002.

24. Field, J. E., and Henderson, D.H., "Corrosion of Metals in Contact with New Refrigerants/Lubricants at Various Moisture and Organic Levels", ASHRAE Transactions: Vol. 104, Pt 1A, pp 210-220, 1998.

25. Field, J.E., "Develop Corrosion Data with Metals of Construction and New Refrigerants/Lubricants at Various Moisture and Organic Levels", ASHRAE Project 887RP, Final Report, January 31, 1997. 
26. Field, J., "Method for Determining Refrigerant and Lubricant Decomposition for HFCs and POEs Using Ion Chromatography", Seminar 28, ASHRAE Winter Meeting, Chicago, 1995.

27. Finkenstadt, W.R., and Mulay, A., "Improving Hydrolytic Stability of POE Lubricants by the Addition of Acid Catchers", $8^{\text {th }}$ Intl. Ref. Conf., pp 249-256, 2000.

28. FLUITEC International, "RULER Techniques and Voltammetry: What is the Remaining Useful Life?", Education Part 5, pp 1-13, Mar 19, 2002.

29. Gibb, P.T., Whittaker, A.J., Corr, S., Yost, R., and Shoji, M., "Determination of Properties of Highly Optimized Polyol Ester Lubricants", ASHRAE Transactions: Vol. 105, Pt. 2, pp 995-999, 1999.

30. Hamblin, P.C., Kristen, U., and Chasan, D., "Ashless Antioxidants, Copper Deactivators and Corrosion Inhibitors: Their Use in Lubricating Oils"; Lubr. Sci. 2, 4, 1989.

31. Hansen, P.E., and Snitkjaer, L., "Development of Small Hermetic Compressors for HFC $134 \mathrm{a} ", 18^{\text {th }}$ Intl. Congr. of Refrig. pp $1146-1150,1991$.

32. Henderson, D.R., Practical Guide, Lubrication and Tribology, ASHRAE Journal, Vol. 42, No. 2, pp 52-61, February 2000.

33. Herbe, L., and Lundqvist, P., "CFC and HCFC Refrigerants Retrofit - Experiences and Results", Intl. J. Refrig. 1, pp 49-54, 1997.

34. Herguth, W.R., and Phillips, S., "Comparison of Common Analytical Techniques for Voltammetric Analysis of Antioxidants in Industrial Lubricating Oils"; STLE Annual Meeting Kansas City, 1994,

35. Hiodoshi, S., Matsuura, H., Kanayama, T., Nishikawa, K and Nomura, M., "Practical Use of Polyvinylether as the Lubrication Oil for Alternative, Compressor and System", Unpublished paper, Intl. Inst. Refrig. Reference 2000-0713, 1999.

36. Huttenlocher, D.F., "Chemical and Thermal Stability of Refrigerant-Lubricant Mixtures with Metals", ARTI MCLR Final Report DOE/CE/23810-5, Air-Conditioning and Refrigeration Technology Institute, Arlington, VA, 1992.

37. Hsu, S.M., Ku, C.S., and Pei, P.T., "Oxidative Degradation Mechanisms of Lubricants", Aspects of Lubricant Oxidation, ASTM STP 916, pp. 27-48, 1986.

38. Iizuka, T., Ishiyarna, A., Hata, H., and Sugano, T., "Study of Technology for Refrigerant Applications for HCFC-22 Alternate Refrigerants", Intl. Ref. Conf., pp 515 - 519, 1996. 
39. Iizuka, T., Ishiyama, A., Hata, H., and Sato, K., "Reliability Study of HFC134a Compressor for Refrigerator", Proc. Intl. Compressor Eng. Efficiency Conference, Purdue Univ., Vol. 1, 1996.

40. Ishida, Y., Nishiwaki, F., and Ikoma, M., "A Study on Lubricity of Polyester for Alternative Refrigerant HFC-134a”, Proc. Compressor Eng. Conf., 1, pp 407-412, 1996.

41. Jefferies, A., and Ameye. J., "RULER ${ }^{\mathrm{TM}}$ and Used Engine Oil Analysis Programs"; Pres. Soc. Trib. Lubr. Eng. at the World Trib. Congress in London, United Kingdom, 1997, Lubr. Eng, May 1998.

42. Jensen, R.K., Korcek, S. and Zinbo, M., "Oxidation and Inhibition of Pentaerythritol Esters"; J. Syn. Lubr. (1) 91-105, 1984.

43. Kauffman, R.E., "Chemical Analysis and Recycling of Used Refrigerant from Field Systems", ASHRAE Trans. Paper 3555 (RP-601), pp 128-136, 1990.

44. Kauffman, R.E., and Ameye, J., "Ruler Analyses to Determine the Antioxidant, Total Acid Number, and Total Base Number Values of Used Diesel Engine Oils to Enhance Condition Monitoring Programs"; VIT Sympos. 171, pp 183-197, 1997, (COMADEM '97, Intl. Congress and Exhibition on Condition Monitoring and Diagnostic Engineering Management, Vol. 1, 1997.

45. Keller, M.A., and Saba, C.S., "Monitoring of Ester Base Lubricants by Dielectric Constant”, J. Soc. Trib. Lubr. Eng., 45, June 1989

46. Komatsuzaki, S., and Homma, Y., "Antiseizure and Antiwear Properties of Lubricating Oils Under Refrigerant Gas Environments”, Lubr. Eng. pp 193-198, 1991.

47. Komatsuzaki, S., Homma, Y., Kawashima, K., and Itoh, Y., "Polyalkylene Glycol as Lubricant for HFC-134a Compressors", Lubr. Eng. pp 1018-1025, 1991.

48. Korcek, S., Mahoney, L.R., Johnnson, M.D., and Otto, K., "Antioxidant Consumption and Oxidative Degradation of Lubricants"; Nat. Bur. Standards Special Publication 584, Issued 1980.

49. Krevalis, M.A., Duncan, C.B., and Davis, G.W., "The Effect of Structure on the Performance of Polyol Esters as Synthetic Lubricants", $49^{\text {th }}$ Annual Soc. Trib. Lubr. Eng. Meeting, 1994.

50. Lilje, K.C., "The Impact of Chemistry on the Use of Polyol Ester Lubricants in Refrigeration”, ASHRAE Trans. Vol.106, Pt. 2, pp 661-667, June 2000.

51. Lilje, K., Director of Research, CPI Engineering, Personal Communication, March 2003.

52. Mahoney, L.R., “Antioxidants”, Angew. Chem. Int. Edit, 8, 8, pp. 547-555, 1969. 
53. Mahoney, L.R., Korcek, S., Hoffman, S., and Willermet, P.A., "Determination of the Antioxidant Capacity of New and Used Lubricants; Method and Applications", Ind. Eng. Chem. Prod. Res. Dev., 17, 3, 1978.

54. Mahoney, L.R., Korcek, S., Jensen, R.K., and Zinbo, M., "The Micro-stirred Flow Reactor: Potential Utilization for Kinetic and Mechanistic Studies of the Reaction of Additives in Fuels and Lubricants”, Amer. Chem. Soc., Div. Petrol. Chem. Preprint, 21, 4,1978 .

55. Mayo, F.R., "Free-Radical Autoxidations of Hydrocarbons", Accounts of Chem. Res. 1, 7, July, 1968.

56. Murray, S.F., and Ling, F.F., "Opportunities for On-line Machinery Sensing", Energy Week Conference \& Exhibition, Houston, Texas, Jan 29 - Feb 2, ASME International, 4, 4, 1996.

57. Pauling, L., "The Nature of the Chemical Bond and the Structure of Molecules and Crystals: An Introduction to Modern Structural Chemistry", Cornell University, $3^{\text {rd }}$ edition, 1960.

58. Payne, A., Quality Control Supervisor, Intertek Testing Services, Personal Communication, March 2003.

59. Reimer, A., and Hansen, P.E., "Analysis of R-134a Cabinets from the First Series Production in 1990, Proc. 1996 Intl. Refrig. Conf., July 1996.

60. Rohatgi, N.T., Whitmire, T.T., and Clark, R.W., "Chloride, Fluoride and Acidity Measurements in Refrigerants", ASHRAE Trans., Vol. 107, Pt. 1, pp 141-146, 2001.

61. Sasaki, A., Uchiyama, S., and Yamamoto, T., "Free Radicals and Oil Auto-Oxidation Due to Spark Discharges of Static Electricity", $53^{\text {rd }}$ Ann. Meet, Detroit, Lubr. Eng., 1999.

62. Sato, S., Minemura, Y., and Todoroki, T., "Chemical Analysis for Capillary Sludge for POE/HFC”, Proc. Intl. Sym. HCFC Alternative Refrigerants, Kobe 1998.

63. Sekiya, S., Shirafuji, Y., Kawaguchi, S., Kato, T., and Izawa, T., "Alkylbenzenes for Split Air-Conditioners with R-410A - Part 1; Reliability Evaluation of Compressors", Proc. 1998 Intl. Compressor Engineering Conf., 2, pp 465-470, Perdue 1998.

64. Shimomura, Y., Takigawa, K., Tagawa, K., and Sunami, M., "New Ester Type Refrigeration Lubricants Primarily for Household Refrigerators", $8{ }^{\text {th }}$ Intl. Refrig. Conf., pp 281-287, 2000.

65. Skoog, D.A., and West, D.M., "Fundamentals of Analytical Chemistry", Holt, Rinehart and Winston, $3^{\text {rd }}$ Edition, 1976. 
66. Spauschus, H.O., "Copper Transfer in Refrigerant-Oil Solutions", ASHRAE Trans., ASHRAE Journal, Vol. 5, No. 89, 1963.

67. Sunami, M., Takigawa, K., and Suda, S., "Optimization of POE Type Refrigeration Lubricants”, Proc. 1994 Intl. Refrig. Conf. pp 153-158, 1994.

68. Sundaresan, S.G., "Industry Experience with HFC Refrigerants - Contaminant Control: Key to Hermetic System Integrity”, Proc. Inst. R., 2, pp 1-9, 1997.

69. SUVA Refrigerants Technical Bulletin ARTD-32, "Factors Affecting the Copper Plating Phenomena with HFC-134a/Polyalkylene Glycol Refrigeration Fluids", Dupont Chemicals Inc., 1992.

70. Suva Technical Bulletin ARTD-32, "Factors Affecting the Copper Plating Phenomena with HFC-134a/Polyalkylene Glycol Refrigeration Fluids”, Dupont Chemicals, 1992.

71. Takaichi, K., and Sakai, M., "Lubricants for HFC-134a Compatible Compressors", Proc. Intl. Conf. Compressor Eng., 3, pp 1035-1044, 1992.

72. Tarbell, L.E., “Analysis of Used Refrigeration Compressor Lubricants", Texaco Inc., LUBRICATION 57, 6, 1971.

73. Tayler, P.J., Corr, S., Dekleva, T., Nishizawa, T., Khatib, N., Randles, S.J., and Stewart, A., "Development and Experience for Use with R-134a Domestic Refrigerators", Pres. Intl. CFC and Halon Alternatives Conf., October 1994.

74. Tazaki, T., Konishi, T. and Nagamatsu, N., "Development of Polyvinylether Refrigeration Oil for Hydrofluorocarbon Air-Conditioning Systems", ASHRAE Trans. Vol. 104, Pt. 1B, pp 1341-1346, 1998.

75. Thomas, H.P., and Pham, H.T., "Evaluation of Environmentally Acceptable Refrigerant/ Lubricant Mixtures for Refrigeration and Air Conditioning”, Pres. at SAE Passenger Car Meeting and Exposition, Dearborn, Michigan, September 1989.

76. Tominaga, S., Takagi, M., Takesue, M. and Tazaki, T., "Practical Stability Performance of Polyvinylether with HFC Refrigerants", $15^{\text {th }}$ Intl. Compressor Eng. Conf., pp 201-206, 2000 .

77. van Leeuwen, W., "Use of RULER" ${ }^{\mathrm{TM}}$ for the Determination of Critical Antioxidant Concentration in Ester Based Hydraulic Fluids", Pres. Soc. Trib. Lubr. Eng. Ann. Meeting Detroit, 1998.

78. Vinci, J.N., and Dick, D.L., "Polyol Ester Lubricants for HFC Refrigerants: A Systematic Protocol for Additive Selection", Proc. Intl. CFC Halon Alternative Conf., pp 78-87, 1995. 
79. Willermet, P.A., Mahoney, L.R. and Haas, C.M., "The Effects of Antioxidant Reactions on the Wear Behavior of a Zinc Dialkyldithiophosphate", Preprint No. 78-AM-1B-1 Amer. Soc. Lubr. Eng. $33^{\text {rd }}$ Ann. Meeting, Dearborn, Michigan April 17-20, 1978

80. Wojtkowski, E.F., "System Contamination and Cleanup", ASHRAE Journal, Vol. 6, No. 6, pp 49-52, June 1964.

81. Yost, R., Lab Director, National Refrigerants, Personal Communication, March 2003. 
APPENDIX 1

Bibliography Synopses 
Ameye, J., "Rapid and Cost-effective Determination of the Remaining Useful Life (RUL) of Industrial Lubricants by Voltammetric Techniques”, Pres. Oil Anal. Conf., Tulsa, Oklahoma, 24-26 ${ }^{\text {th }}$ October 2000.

According to the author, antioxidant depletion can be determined by the following methods:

1. thermal-oxidative stressing techniques like RPVOT, TOST, HPDSC

2. electrochemical - voltammetric techniques $\left(\mathrm{RULER}^{\mathrm{R}}\right)$

3. instrumental techniques - FTIR, HPLC

The author compares RULER, RPVOT (ASTM D2272) and TAN (ASTM D664).

RULER offers a number of advantages over the other two methods:

- low cost

- allows trending by combining it with other techniques (particle counting, viscosity, water content etc.)

- proactive information by allowing to make proactive decisions since it correlates with TAN data

- portable, light weight instrument for on-site analysis

- data-exchange capabilities (Windows environment)

Bakunin, V.N., and Parenago, O.P., "A Mechanism of Thermo-oxidative Degradation of Polyol Ester Lubricants”, J. Syn. Lubricants, 9, 2, pp 128-143, 1992.

The Russian authors of this review address the mechanism of thermo-oxidative degradation of polyol ester lubricants. Although frequently quoted the paper is not for the impatient reader. Possible degradation mechanisms are dealt with in great detail. Features of high temperature oxidation summarized. This review is heavily referenced and comprehensive in the topics addressed and deals with the composition of the oxidation products. Here too as in other papers the peak broadening, when plotting relative amounts of chemical compounds versus molecular weight (abscissa), is mentioned for the oxidized sample as compared to the original oil. This is a property, which was observed at Powertech Labs Inc. in the case of 'simulated distillation' (ASTM D5307) for the same reasons and should be exploited. These authors express the view in the conclusions that many aspects of the oxidation mechanism need elucidation. In respect to practical applications the formation of high molecular weight compounds (HMWC) as expressed in viscosity increase and sludge or deposit formation should be studied. Powertech Labs Inc. agrees with that statement.

Bartnikas, R., “Electrical Insulating Fluids”, ASTM Monograph 2, Engineering Dielectrics Volume 3, 1994.

This book provides a comprehensive, in-depth examination of insulating oils including the electrical, chemical and physical performance of the fluids. Two of the five chapters are devoted to the chemical and physical characteristics of mineral oils used in the electrical industry. Topics include the chemical degradation processes and testing methods to assess the condition of the oil as well as the molecular structure and chemical components of the oils. 
Bowman, W.F., Stachowiak, "New Criteria to Assess the Remaining Useful Life of Industrial Turbine Oils”, J. Soc. Trib. Lubr. Eng., July 1996

The authors developed a method for the determination of the remaining useful life (RUL) of commercially available steam turbine oil using the technique of sealed capsule differential scanning calorimetry (SCDSC). The fundamentals of this technique are the determination of the so-called "induction time". The induction time relies on the formation of peroxides and thus free radicals. This technique in conjunction with artificially oxidized turbine oils and FTIR infrared spectroscopy permitted the design of a zone map, which reflects the RUL of an oil at any given time. Good correlation was achieved. The attraction of SCDSC, according to the authors, is that it is precise, uses only micro-liter quantities of sample and is faster than other commercially available techniques. The method does not recommend itself for field investigations.

Boyde, S., and Wilton, U., "Hydrolytic Stability of Synthetic Ester Lubricants", J. Syn. Lubr., 16, 4, pp 297-312, 1999.

The paper reviews the chemistry of ester lubricants including esterification as well as hydrolytic decomposition mechanisms. Acid and base catalyzed hydrolysis are discussed as well as factors affecting hydrolytic stability including the chemical structure of the ester, initial TAN value, metals, acidic additives as well as acid catcher additives. The thermal and oxidative stability of polyol esters are also discussed. Data is presented on the results of accelerated hydrolysis studies including sealed tube testing.

Cavestri, R.C., "Potentially Useful Polyolester Lubricant Additives. An Overview of Antioxidants, Antiwear, and Antiseize Compounds”, Proc. Intl. Ref. Conf. West Lafayette, Indiana, July 23 - 26, 1996

The author reviews the use of additives as relevant to polyolester lubricants. He discusses their use in CFC and HCFC containing compressors and the effects on other system components such as the different metal surfaces, sealing materials etc. Additive selection, antioxidants, antiwear and Antiseize substances are discussed in brief chapters. The author emphasizes that the desired lubricant in HFC compressor systems is with polyesters that have great affinity for metal surfaces. The polarity of additive in relationship to polyolester has to be considered.

Cavestri, R.C., Falconi, E., Ruona, K.S., and Schooley, D.L., "Effect of Selected Contaminants in Air Conditioning and Refrigeration Equipment”, Air-Conditioning and Refrigeration Technology Institute, ARTI MCLR Final Report Project 665-53000, DOE/CE/23810-111, December 2000.

This extensive study investigated the statistical significance of water; organic acid and air contaminants in selected refrigerants on compressor wear. The study included sealed tube tests at two temperatures as well as 12,000 hour runs using 128 compressors. The refrigerants included R-507A containing 4\% R-502, R-407C containing 4\% R-22, R-134a containing 4\% R12 versus R-22 containing no contaminant refrigerant. A polyol ester lubricant was used with the first three refrigerants whereas mineral oil was used as the lubricant for R-22. Low levels of organic acid and water both contributed to system corrosion but the process was greatly 
accelerated by the presence air. The amount of corrosion with the R-22 system was significantly greater than that found with the POE systems.

DeVos, R., "R-134a Qualification - Industry Refrigeration Capillary Data”, ASHRAE Transactions: Vol. 103, Pt. 2, pp 640-648, 1997.

The paper presents results obtained from an investigation of the effect of organic chloride levels $(50-500 \mathrm{ppm})$, moisture content $(100-400 \mathrm{ppm})$ and the type of oil and compressor on capillary tube plugging in test systems using R-134a/POE. Parameters monitored in the study included moisture content, dissolved iron and total acid. It was found that elevated levels of organic chlorides and moisture resulted in accelerated capillary system plugging. The deposits formed on the capillary tube inlets were identified by infrared analysis to be predominantly carboxylic acid salts.

Duncan, C., Reyes-Gavilan, J., Costantini, D. and Oshode, S., “Ashless Additives And New Polyol Ester Base Oils Formulated for Use in Biodegradable Hydraulic Fluid Applications”, J. Soc. of Trib. and Lubr. Eng., Vol. 58, No. 9, September 2002.

This paper introduces the topic of environmentally friendly polyol esters, their basic chemistry and remarkable thermal stability. The topic of ashless additive technology is part of the discussion. Polyol esters (POE) were investigated in the laboratory and their properties are contrasted under different test conditions (ASTM, DIN, US Steel ---) with those vegetable oils. The authors conclude that the POEs have been properly stabilized and outperform at least in hydrolytic stability vegetable oils.

Field, J. E., and Henderson, D.H., "Corrosion of Metals in Contact with New Refrigerants/Lubricants at Various Moisture and Organic Levels", ASHRAE Transactions, Vol. 104, Pt. 1A, pp 210-220, 1998.

This paper summarizes the results obtained in ASHRAE Project 887-RP which investigated the effect of moisture or acid level on corrosion of metals in contact with R-134a and an additivefree branched polyolester lubricant. Accelerated aging experiments were performed in sealed tubes at three elevated temperatures. Significant corrosion occurred at higher temperatures in the presence of iron or steel resulting in precipitation whereas there was little or no effect with copper or aluminum. The effect on the acidity levels was determined over time using titrimetry and ion chromatography and the effect on metals was followed by electron microscopy and infrared analysis. 
Gibb, P.T., Whittaker, A.J., Corr, S., Yost, R., and Shoji, M., "Determination of Properties of Highly Optimized Polyol Ester Lubricants”, ASHRAE Trans., Vol. 105, Pt. 2, pp 995999, 1999.

The paper reviews the analytical methods that are used for the development, quality control and monitoring of POE lubricant systems. Key parameters identified for in-service assessment of the system include viscosity, moisture (50 ppm max.), metals content, additive levels and residual mineral oil (max. $<1 \%)$. Recommendations are made regarding critical TAN values which require action.

Henderson, D.R., Practical Guide, Lubrication and Tribology, ASHRAE Journal, Vol. 42, No. 2, pp 52-61, February 2000.

The author reviews tests which should be performed for condition assessment of compressors. The tests include smell, color, acidity, moisture, viscosity, additive levels and dissolved metal content.

Herbe, L., and Lundqvist, P., "CFC and HCFC Refrigerants Retrofit - Experiences and Results”, Intl. J. Refrig. 1, pp 49-54, 1997.

The paper discusses the effects of acidity, moisture and residual mineral oil in retrofitted units, which had been converted from R-12 to R-134a. A database was established which included TAN, moisture content and dissolved metal results from the analysis of 600 lubricant samples obtained before and after the conversion. Based on the results of an industry survey, the authors suggested that problems due to acid formation and copper plating in the retrofitted systems can be avoided provided the residual mineral oil level is below $1 \%$ and the moisture content is maintained below $50 \mathrm{ppm}$.

Herguth, W.R., and Phillips, S., "Comparison of Common Analytical Techniques for Voltammetric Analysis of Antioxidants in Industrial Lubricating Oils"; STLE Annual Meeting Kansas City, 1994.

Although the authors did not mention the name RULER ${ }^{\mathrm{TM}}$, it appears that it was the instrument of choice used for these investigations. The technique was compared with common methods of lubricant analysis to evaluate its usefulness. The authors reached the conclusion that "changes in the acidity and viscosity can be predicted using the antioxidant level as a tool for the evaluation of the remaining useful life of the lubricant."

The authors provide correlation coefficients between voltammetry and RBOT and voltammetry and DSC for six (6) oil types. Problematic data are encountered for synthetic hydrocarbon and hydraulic oil (low correlation!).

Hsu, S.M., Ku, C.S., and Pei, P.T., “Oxidative Degradation Mechanisms of Lubricants”, Aspects of Lubricant Oxidation, ASTM STP 916, pp. 27-48, 1986. 
These investigators measured the antioxidant capacity of the oil samples under controlled conditions by free radical titration. This titration method measures the formation of free radicals in lube oils. The authors suspect a metal catalyzed polymerization mechanism for increases in viscosity and the formation of oil insoluble products.

Jefferies, A., and Ameye. J., "RULER ${ }^{\mathrm{TM}}$ and Used Engine Oil Analysis Programs"; Pres. Soc. Trib. Lubr. Eng. at the World Trib. Congress in London, United Kingdom, 1997, Lubr. Eng, May 1998.

This paper provides a precision statement for the RULER ${ }^{\mathrm{TM}}$ technique, which is $2.5 \mathrm{RSD}$ for the additives used in diesel engine oils. Concerning the limitations of the RULER technique there are two observations reported.

- The RULER ${ }^{\mathrm{TM}}$ shall not be used as a stand-alone technique but in conjunction with other analytical data

- "The RULER ${ }^{\mathrm{TM}}$ cannot be used to compare two or more oils with different antioxidant levels as a tool to differentiate the quality of one oil over another."

Jensen, R.K., Korcek, S. and Zinbo, M., “Oxidation and Inhibition of Pentaerythritol Esters”; J. Syn. Lubr. (1) 91-105, 1984.

These authors suggest a predictive inhibition model for pentaerythrityl tetraalkanoates (PETA) and pentaerythrityl tetra heptaethanoate $(\mathrm{PETH})$ based on the structural and kinetic parameters for substrate and antioxidant. Although of theoretical interest to this reviewer, no direct practical application in the framework of the present review exists.

Kauffman, R.E., “Chemical Analysis and Recycling of Used Refrigerant from Field Systems”, ASHRAE Trans. Paper 3555, (RP-601), pp 128-136, 1990.

Samples of CFC and HCFC refrigerants and lubricants from 39 normally operating systems as well as failed units which had operated for periods ranging from a few months to 27 years of months were collected and quantitatively analysed to determine the contaminant levels. The total acid content and strong acid concentrations were determined for the refrigerants as well as the lubricants. Other parameters included chloride and fluoride levels, moisture content, high boiling residues, particulates, and volatile impurities. Results from a laboratory recycling study on used refrigerants are also presented.

Korcek, S., Mahoney, L.R., Johnnson, M.D., and Otto, K. “Antioxidant Consumption and Oxidative Degradation of Lubricants”; Nat. Bur. Standards Special Publication 584, Issued 1980.

This is an excellent paper from the point of view that it describes in detail the experimental determination of 'free radicals' or what is equivalent the determination of 'antioxidants concentrations' based on first principles. The method is an excellent reference method to which 
to correlate new techniques such as Powertech Labs Inc.'s 2,2-Diphenyl-1-picrylhydrazyl (DPPH) technique for free radicals or the RULER ${ }^{\mathrm{TM}}$ method.

Lilje, K.C., "The Impact of Chemistry on the Use of Polyol Ester Lubricants in Refrigeration”, ASHRAE Trans. Vol. 106, Pt. 2, pp 661-667, June 2000.

This paper discusses the changes in refrigeration system chemistry as a result of the switch to HFC/POE systems from the older CFC/mineral oil systems. The author discusses the steps that have been implemented by the industry to address initial problems such as hydrolytic stability and compatibility with plastics, elastomers and residual processing chemicals. Data are presented which indicate that copper plating is not a problem with POE lubricants unless residual $\mathrm{CFC} / \mathrm{mineral}$ oil is present in the system.

Mahoney, L.R., “Antioxidants”, Angew. Chem. Int. Edit., 8, 8, pp. 547-555, 1969.

This is a very in depth treatment and review of free radical initiated liquid phase oxidation of hydrocarbons; it is about recent findings addressing the kinetics and thermodynamics of inhibition by "antioxidants". The discussion includes topics such as the effects of $\pi$-electron systems adjacent to the reactive hydrogen in various hydrocarbons, inhibition periods, kinetics and mechanism of inhibition by phenols, hindered phenols, non-hindered phenols and hydroquinones. The thermodynamics, bond energies and synergistic behavior of phenols are reviewed followed by a brief treatment of aromatic amines as antioxidants.

Mahoney, L.R., Korcek, S., Hoffman, S., and Willermet, P.A., "Determination of the Antioxidant Capacity of New and Used Lubricants; Method and Applications”, Ind. Eng. Chem. Prod. Res. Dev., 17, 3, 1978.

This paper demonstrates the determination of the total effective concentration of chain stopping antioxidant species present in new and used lubricants. The results for antioxidant depletion correlate to, in the case of engine oils, vehicle mileage. In the case of refrigeration systems similar data should relate to "useful life left". The reason for this predictive power comes from the fact that the antioxidant (man made or natural) decay occurs long before other lubricant properties such as viscosity, TAN, or the formation of deposits change.

Mayo, F.R., “Free-Radical Autoxidations of Hydrocarbons”, Accounts of Chem. Res. 1, 7, July, 1968.

This paper is a thorough primer on free radical auto-oxidation of hydrocarbons and the applicable experimental methods. It provides a convenient approach to the problem of polyol ester based lubricants and the methods to detect and quantify the same.

Reime, A., and Hansen, P.E., "Analysis of R-134a Cabinets from the First Series Production in 1990, Proc. 1996 Intl. Refrig. Conference, July 1996. 
Results are presented from a Danish study of seven apartment refrigerators equipped with R134a/POE and three units containing R-12 with mineral oil lubricant after five years of operation. Parameters examined included TAN values, moisture contents of the lubricants and driers, refrigerant degradation, and capillary flow reduction. Examination of the dissected compressor parts showed that no severe wear or copper plating had occurred in any of the units.

Spauschus, H.O., “Copper Transfer in Refrigerant-Oil Solutions”, ASHRAE Journal, Vol. 5, No. 89, 1963.

A laboratory study was performed to investigate the mechanism for copper plating in refrigeration systems. Accelerated aging tests were carried out using R-12, R-13, R-22 and R-23 refrigerants and two types of mineral oils (paraffinic and naphthenic). The reactions were followed by determining both the dissolved copper and plated copper levels after a thirty day aging period. Potential copper plating mechanisms are discussed

Suva Refrigerants, "Factors Affecting the Copper Plating Phenomena with HFC134a/Polyalkylene Glycol Refrigeration Fluids”, Dupont Chemicals Technical Bulletin ARTD-32, 1992.

The copper plating characteristics of R-134a/PAG determined in sealed-tube tests are compared to those reported in the literature for CFC refrigerants with either mineral oil or alkyl benzene lubricants. The effect of contaminants such as air, CFC and aged mineral oil on the copper plating characteristics of R-134a/PAG are also discussed.

Tazaki, T., Konishi, T, and Nagamatsu, N., "Development of Polyvinylether Refrigeration Oil for Hydrofluorocarboncarbon Air-Conditioning Systems”, ASHRAE Transactions: Vol. 104, Pt. 1B, 1998.

The authors compared the capillary plugging tendency of contaminant-doped POE and PVE lubricants with R-134a refrigerant in laboratory test stands. The contaminants for the tests were isolated from brand-new refrigerator parts including a heat exchanger and compressor motor components by solvent extracting the parts with chloroform, hexane, methanol, methyl isobutyl ketone and water. The contaminants were identified using GC-MS, FTIR and SEM-EDS and their solubility characteristics in the two lubricants were evaluated. The material found in the capillary plugs was found to be very similar to the added contaminants but also contained some copper salts and a PVE additive. The PVE systems ran longer without plugging than the POE systems which was attributed to the better solubility of the contaminants in the PVE lubricant.

Thomas, H.P., and Pham, H.T., "Evaluation of Environmentally Acceptable Refrigerant/Lubricant Mixtures for Refrigeration and Air Conditioning”, Presentation at SAE Passenger Car Meeting and Exposition, Dearborn, Michigan, September 1989.

The authors compare laboratory test results obtained with R-134a/PAG and R-12/mineral oil refrigerant/lubricant mixtures. The parameters examined include miscibility, solubility, stability, lubricity and elastomer compatibility. Copper plating was found to be substantially reduced with the HFC/PAG system compared to the CFC/mineral mixture. The stability of the HFC/PAG 
system was reported to be minimally affected by hydrolysis but the presence of air significantly increased the amount of fluoride ion produced. Air had little effect on the $\mathrm{CFC} / \mathrm{mineral}$ oil system but both chloride and fluoride concentrations increased with increased water concentrations.

\section{van Leeuwen, W., "Use of RULER ${ }^{\mathrm{TM}}$ for the Determination of Critical Antioxidant Concentration in Ester Based Hydraulic Fluids”, Pres. Soc. Trib. Lubr. Eng. Ann. Meeting Detroit, 1998.}

This is another paper, which evaluates RULER ${ }^{\mathrm{TM}}$ for the determination of the "useful life" of ester based hydraulic fluids by measuring the concentration of the remaining antioxidant package. This inhibitor package will deplete until the ester based hydraulic fluid begins to degrade/polymerize at a higher rate. The fluids tested contain primary and/or secondary oxidation inhibitors, which in combination act synergistically. The primary inhibitors react as free radicals scavengers and consist of hindered phenols, aminophenols, aliphatic amines and/or aromatic amines preventing polymerization reactions. The secondary inhibitors eliminate peroxides $\mathrm{ROOH}$ by converting them to harmless $\mathrm{ROH}$ and are usually sulfur containing phenols and/or phosphites. The authors determine the acid number and viscosity of the oil samples in conjunction with RULER ${ }^{\mathrm{TM}}$. The remaining life (RUL) of field samples was estimated by comparing RULER ${ }^{\mathrm{TM}}$ data with those for acid number and viscosity at $40^{\circ} \mathrm{C}$. It appears that the voltammetric RULER results did not replace the need for acid number and viscosity.

\section{Wojtkowski, E.F., "System Contamination and Cleanup”, ASHRAE Journal, 6, 6, pp 49- 52, June 1964.}

Total acid numbers were determined for used mineral oil lubricants from six hundred and seventy-eight R-22 systems which were operating normally or which had suffered compressor problems ranging from darkening of the wire enamel to charring of the motor insulation. The probability distribution curves for the two sets of data intersected at $0.05 \mathrm{mg} \mathrm{NaOH} / \mathrm{g}$ of oil which was selected as the critical TAN value for mineral oil systems with CFC refrigerants. Details are also provided on an acid test kit developed for the field evaluation of lubricant TAN values. 
APPENDIX 2

Nomenclature

\title{
NOMENCLATURE
}

\author{
AB Alkylbenzene \\ Al Aluminum \\ ARI Air-Conditioning and Refrigeration Institute \\ ARTI Air-Conditioning and Refrigeration Technology Institute \\ ASHRAE American Society of Heating, Refrigerating, and Air-Conditioning Engineers
}




$\begin{array}{ll}\text { CFC } & \text { Chlorofluorocarbon } \\ \text { Cl } & \text { Chlorine } \\ \mathrm{CO}_{2} & \text { Carbon Dioxide } \\ \mathrm{Cu} & \text { Copper } \\ \mathrm{CV} & \text { Cyclic Voltammetry } \\ \text { DOE } & \text { U.S. Department of Energy } \\ \text { DPPH } & \text { 2.2-Diphenyl-1-picrylhydrazyl } \\ \text { DSC } & \text { Differential Scanning Calorimetry } \\ \text { F } & \text { Fluorine } \\ \text { Fe } & \text { Iron } \\ \text { FTIC } & \text { Fourier Transformation Infrared Spectroscopy } \\ \text { GC-MS } & \text { Gas Chromatography-Mass Spectroscopy } \\ \text { H } & \text { Hydrogen } \\ \text { HCl } & \text { Hydrochloric Acid } \\ \text { HCFC } & \text { Hydrochlorofluorocarbon } \\ \text { HF } & \text { Hydrofluoric Acid } \\ \text { HFC } & \text { Hydrofluorocarbon } \\ \text { HOPOE } & \text { Highly Optimized Polyol Ester } \\ \text { HSPOE } & \text { Hydrolytically Stable Polyol Ester } \\ \text { IC } & \text { Ion Chromatography } \\ \text { ICP } & \text { Inductively Coupled Plasma Emission Spectroscopy } \\ \text { IEE } & \text { Institute of Electrical Engineers } \\ \text { IEEE } & \text { Institute of Electronic and Electrical Engineers } \\ \text { LSV } & \text { Linear Sweep Voltammetry } \\ \text { MA } & \text { Milliamperes } \\ \text { MO } & \text { Mineral Oil } \\ \text { PAG } & \text { Polyalkylene Glycol } \\ \text { PE } & \text { Pentaerythritol } \\ \text { pH } & \text { Degree of Acidity or Alkalinity of a solution } \\ \text { PET } & \text { Polyethylene Terephthalate } \\ \text { POE } & \text { Polyol Ester } \\ \text { PPG } & \text { Polypropylene Glycol } \\ \text { PPM } & \text { Parts per million } \\ \text { PVE } & \text { Polyvinyl Ether R }{ }^{2} \\ \text { RSD } & \text { Relative Standard Deviation } \\ \text { RUL } & \text { Remaining Useful Life } \\ \text { SCDSC } & \text { Sealed Capsule Differential Scanning Calorimetry } \\ \text { SEM } & \text { Scanning Electron Microscopy } \\ \text { STLE } & \text { Society of Tribologists and Lubrication Engineers } \\ \text { TAN } & \text { Total Acid Number } \\ \text { TPP } & \text { Triphenylphosphate } \\ \text { V } & \text { Volts } \\ & \end{array}$

